\title{
Do Extra Ingredients on the Package Lead to Extra Calorie Estimates?
}

\section{Introduction}

People love to mix food up, for instance, coffee with milk, cake with fruit, vegetables with mayonnaise, as the added ingredients can bring better taste. A food blogger listed 72 food pairings that he considered as most delicious ones: oatmeal with marmalade, egg roll with seaweed.$^{1}$, and to meet market demands, many food companies launch new foods by adding extra ingredients to their base products. These included, for instance, Oreo's mixed-fruit-and-ice-cream biscuits, Kraft Foods' vegetable-andseaweed Pacific soda crackers, and Yoplait's cherry-and-strawberry yoghurt. How added food ingredients presented on the packaging of the new augmented food affect consumer calorie estimation is however still unclear.

We define an added food ingredient (henceforth AFI) as the added food pairing which declares, and becomes associated with, the new packaged food product. The pairing effectively creates for this new packaged food product a distinct identity. An AFI also goes beyond flavouring/seasoning (i.e. added food flavours; other additives) by altering its nutritional composition (US Food Labelling Regulation, 1996, §14-16). AFIs can be distinctive, visible and strongly evident (e.g. the fruits on the top of a packaged fruitcake) or embedded or blended with other primary ingredients in the new augmented packaged food product (e.g., the chocolate in the chocolate milk, the strawberries in strawberry cookies, the leeks in pork \& leek sausages). AFIs are usually secondary regarding weight reported on the food label given their quantity (e.g., the

\footnotetext{
${ }^{1}$ See http://tieba.baidu.com/p/1921491975.
} 
weight of leeks is usually $9 \%$ compared to $80 \%$ pork in pork \& leek sausages), but they become an essential characteristic and part of the identity of the new augmented packaged food product. As AFIs become increasingly popular among consumers, they bring opportunities and challenges to packaged product portfolio strategies. Extending the product range satisfies heterogeneous consumer needs but also complicates procurement, manufacturing, marketing and ultimately impacts finances (Kang and Montoya, 2014). AFIs also raise great concerns among dietitians and health practitioners and regulators (Haytowitz and Pehrsson, 2018). These warn that AFIs alter food composition per se (Roe et al., 2015), and often mislead consumers by triggering excessive calorie intakes (Wilder et al., 2007). For instance, some studies show that adding a visible healthy AFI to an unhealthy served-on-a-plate base food (e.g., adding fruits on a served cake) results in calorie underestimation of the augmented served-ona-plate food (Chernev and Gal, 2010; Jiang and Lei, 2014).

As a crucial marketing and consumer interaction tool, the packaging of the food product on the retail shelf communicates aesthetic and sensory experiences, brand information and product function assisting consumers in their purchase decisions. It is reported that as many as $90 \%$ of consumers make their purchase decisions after visually evaluating only the front pack of a product (Becker et al., 2015; De Pelsmacker et al., 2011). Packaging cues, both visual and verbal, may become critical heuristics for purchase decisions. Therefore, it is easy to understand that food manufacturers tend to enrich their products appearance by including the AFIs on the food packaging (for instance, the green cucumber on the packaging of Lay's cucumber-flavoured crisps, the 
hazelnuts on the packaging of Hershey's hazelnut chocolate). As the features of AFIs presented may vary, it is unclear whether and how could AFIs on the food packaging affect consumers' calorie estimation of the new augmented packaged food. Answering this question is important given the considerable evidence on the strong link between calorie perception and product purchase, is theoretically distinct from, but also complements what is known for calorie perception and product consumption on a plate / meal evaluation context (Chernev and Gal, 2010; Jiang and Lei, 2014; Roe et al., 2015; Wilder et al., 2007). Purchase and serving on a plate contexts do not overlap time-wise, the former preceding the latter. Food consumption decisions are effectively made at the packaged food purchase stage.

We investigate how AFIs presented on the packaging of the new augmented food affect calorie estimation. Study 1 (1A and 1B) focus on calorie estimation when adding AFIs to an unhealthy or healthy base packaged food. Study 2 tests an underlying mechanism that leads to a calorie underestimation effect which occurs when adding a healthy AFI to an unhealthy packed base food. The two remaining studies investigate two boundary conditions regarding this effect. Specifically, Study 3 looks at whether this effect intensifies when strengthening further the healthiness of the AFIs. Study 4 looks at whether this effect dissipates when the displayed form changes.

We contribute in three ways. We first expand the understanding of the effects of AFIs. Prior studies have primarily focused on the influence of other package/food clues over purchase behavior, e.g., the shape of the packaging, or the image of the food (Deng and Srinivasan, 2013; Madzharov and Block, 2010; Raghubir and Krishna, 1999) or 
looked at AFIs in a served-on-a-plate context; i.e., a meal-calorie evaluation process (Chernev and Gal, 2010; Jiang and Lei, 2014). We investigate the influence of AFIs on calorie estimation and healthiness perceptions in a context not studied before, namely packaged food. Such consideration occurs at an earlier stage than meal evaluations and complements current knowledge.

Next, AFIs' effect is an important topic for studying joint estimation and especially biases when base foods and ingredients are concurrently presented in the evaluation system as product attributes. In doing so, we add to the knowledge about packaging effects (e.g., Deng and Srinivasan, 2013; Kozup et al., 2003; Madzharov and Block, 2010; Silayoi and Speece 2004; 2007; Underwood et al., 2001), visual versus verbal cues (e.g., Carr et al., 1982; Houston et al., 1987; Underwood and Klein, 2002) and calorie-based choice modelling literature (e.g., McFadden, 2001). In doing so, we specifically contribute to food consumption policy debates (e.g., Bazerman, 2001; Chandon and Wansink, 2007; Kivetz and Simonson, 2002; Scheibehenne et al., 2007; Smith and Rogers, 2014; Swinburn et al., 2015; Wansink and Chandon 2006; Wilder et al. 2007) and package-based consumer judgment error and heuristics (e.g., Raghunathan et al., 2006; Schulte-Mecklenbeck et al., 2013; Sevilla and Kahn, 2014; Tversky and Kahneman, 1973).

Moreover, AFIs exert critical influence over consumer judgment as inferential cues for product line extensions. Previous work on product line design has explored the benefits of broadening product lines (e.g., Bayus and Putsis, 1999), product line optimization (e.g., Netessine and Taylor, 2007), product cannibalization (Desai, 2001), 
pricing (Draganska and Jain, 2006; Draganska et al., 2009) and brand equity effects (Randall et al., 1998). Past work has not looked at consumer estimation and perception differences when extending product lines by adding AFIs. Our work has a particular meaning for food firms in not only improving their sales but also safeguarding ethics and diligence towards society in firms' own efforts to combat the obesity epidemic and deal with social accountability issues (Swinburn et al., 2015). The scenarios presented in our study are widespread among food marketers and very close to what food technologists face when developing new products or what nutritionists/ dieticians face when they advise food firms and patients alike. Improving consumers' accuracy in calorie estimation has substantial merit for decisions regarding adding AFIs and their communication.

\section{Theoretical Background}

Presence of AFIs and consumer calorie estimation

During a decision-making process, consumer use of information depends on the usability of that information, their cognitive resources and their motivation (Chaiken, 1980; Tversky and Kahneman, 1973). Chen et al. (1999) clarify that it is the level of that consumer motivation and self-defined goals that guide the selection of sufficiency and confidence thresholds. Concerning food, consumer motivation and self-defined goals may involve lower accuracy targets, lower self-defence motives, weaker links to social impression targets and less strict sufficiency and confidence thresholds. Intensive calculation of calories based on complex combinations of size, volume, ingredients and 
111 other are sidestepped, and simpler health-heuristics are opted for (Chandon and

112 Wansink, 2007). Opted simpler health-heuristics for calorie estimates will take

113 advantage of impressions about food healthiness (Chandon and Wansink, 2007;

114 Raghunathan et al., 2006; Wansink et al. 2004; Wertenbroch, 1998).

The relevance of the healthiness of the packaged base food

117 A healthy base: Healthier food is perceived to contain fewer calories, while an

118 unhealthier more calories. For packaged foods, consumers will also incorporate and

119 integrate visual cues on packaging as health heuristics (e.g. colour, pictures), in their

120 healthiness evaluation (Aydinoğlu and Krishna, 2011). As AFIs are often visually

121 prominent, the perceived healthiness of the augmented packaged food would be

122 determined by the healthiness of both the base food and the AFI that are added on the

123 packaging. When a healthy base packaged food is used, consumers do not need to find

124 excuses for consumption since the healthy base food matches well with consumers'

125 long-term health goal (Giner-Sorolla, 2001). When so, AFI's influencing role

126 diminishes, and the nature of its contribution becomes character-, or flavour- giving to

127 the healthy base food. Then, AFI's relevance is delegated to a subordinate level,

128 regardless of AFI's own healthy or unhealthy nature. The purchase of the main but

129 healthy base food makes consumers believe that they are pursuing a healthy goal. In

130 essence, consumers' commitment in, and taking of actions, to achieve this goal becomes

131 entrenched in the purchase of the base food (Fishbach et al., 2003; Koo and Fishbach,

132 2008). As a consequence, consumers have no conflict to resolve and correspondingly 
can spend resources on calorie assessment, leading them to evaluate the total calories of the combination more rationally and accurately. In such case, it becomes easier for them to conclude a total calorie estimation of the combination to be higher than the calorie estimation of the healthy base food alone. Thus:

HIa: When adding to a healthy base packaged food either a healthy or an unhealthy AFI, consumer calorie estimation is higher than that of the base food alone.

An unhealthy base: When an unhealthy base packaged food is used, consumers face a dilemma as the pleasure and hedonism usually brought by an unhealthy food may be at the cost of long-term health (McClure et al., 2007; Okada, 2005; Prelec and Loewenstein, 1998; Shiv and Fedorikhin, 1999). Therefore, the expected purchase of unhealthy food initiates or intensifies psychological conflict. This conflict refers to the coexistence of positive and negative thoughts or emotions (Kivetz and Simonsonm, 2002; Strahilevitz and Meyers, 1998). The minimizing guilt self-defence motive becomes activated to identify a reason for self-indulgence and reduce conflict or opt for ambivalence which in turn allows for exceptions and deviation $\mathrm{Xu}$ and Schwartz, 2009). Consumers will then be inclined to elevate the weight importance and relevance of low-fat and healthy AFI (Aydinoğlu and Krishna, 2011; Wansink and Chandon, 2006). As healthy AFI can provide consumers with justification for an unhealthy food purchase, excessive attention is paid to the healthiness of the added AFI in consumers' overall new augmented packaged food healthiness evaluations. When the expected (but 
mostly unwanted) conclusion becomes likely (e.g., the augmented food is unhealthier), an AFI-based health-heuristic processing is triggered to achieve a much more wanted conclusion (Chaiken and Eagly, 1989; Eagly and Chaiken, 1993) while simultaneously deserting the base food as a cue (e.g., Kunda, 1990). Attributing a heavy relative weight to the healthier nature of the AFI leads to severe underestimation of overall calories. In contrast, adding an unhealthy AFI to an unhealthy base food collides with consumer demand for a purchase justification and precludes a hedonism-gratification excuse allowing a more accurate (increased) calorie estimation for the new augmented food. Accordingly, we consider:

HIb: When adding to an unhealthy base packaged food an unhealthy AFI, consumer calorie estimation is higher than that of the base food alone.

H1c: When adding to an unhealthy base packaged food a healthy AFI, consumer calorie estimation is lower than that of the base food alone.

External justification: As indicated by Hsee (1995, 1996), consumers select a healthier food that fits to longer health goal rather than an unhealthier indulgent food, if they cannot find a proper excuse to justify the latter. However, even with adequate cognitive resources available, it is quite common for consumers to deliberately seek a justification for the action that they will enjoy more when the criteria for evaluating the decision are ambiguous (Cheema and Soman, 2006). Research from other domains uncover similar results. In reviewing the motivated reasoning research, Kunda (1990, pp. 480, 483) summarized that "the biasing role of goals is thus constrained by one's ability to 
construct a justification for the desired conclusion: people will come to believe what they want to believe only to the extent that (motivated) reason permits."

Consumers opting for a status of ambivalence or conflict reduction is facilitated when additional external source justification exists (Cheema and Soman, 2006; Okada, 2005). The presenting of a healthy AFI on an unhealthy packaged base food provide excuses for temporal disqualification of utilitarian goals in favor of hedonic and taste enjoyment goals together with an easier reconciling conflict and fact acceptance. The emotional and adverse experiences of self-blame, regret, or remorse dissipate, guilt (Chernev, 2011) becomes accepted and excused, and indulgent consumption is temporarily permitted. When provided with an external justification excuse, a healthy AFI-based adjustment is not needed any longer for the consumption of an unhealthy base, and estimation reverts closer to the facts. Thus:

H2: Provided that an external justification for an indulgent consumption is present, the underestimation effect from adding to an unhealthy base food a healthy AFI is mitigated.

\section{Visual Presentation and Verbal Presentation of the Packaging}

Regarding purchase decisions, product packaging cues operate in different ways (Aydinoğlu and Krishna, 2011; Raghubir and Krishna, 1999; Sevilla and Kahn, 2014). Visual packaging information attracts consumers' attention first and set boundary expectations for the use of the verbal elements; the latter is serving at a later stage as an 
'advance judger' platform of the visual ones (Alesandrini and Sheikh,1983; Houston et al., 1987). Meanwhile, compared with verbal information, images are more efficient in motivating people's memory-stored sensory information (e.g., smell, taste) (MacInnis and Price, 1987; Underwood and Klein, 2002) and provide consumers with diagnostic heuristics for their judgment and purchase choice (Kisielius and Sternthal, 1986). Visual cues are also more easily and faster accessed (Carr et al., 1982). When in heuristic mode, visual cues are more likely to affect consumers' judgment than verbal information (Aydinoğlu and Krishna, 2011). Schulte-Mecklenbeck et al. (2013) show that, though verbal cues are critical (weight equally as other studied cues such as price, calorie information etc.), visual cues are most important in participants' food choice decisions. The visual-based effect and its salience will maintain the calorie underestimation effect of adding a healthy AFI to an unhealthy base food. In contrast, a verbal element likely dissipates the effect because it obliges consumers to engage in a more elaborate cognitive process forcing them to delve longer and deeper in their own judgment (van Osselaer, 2008: 721), undermine the effect of the triggered heuristic, and the salience of the stimuli is downgraded (Rebollar et al., 2017) reversing earlier estimations. This does not mean that verbal cues are unlikely to activate the diagnostic heuristic for judgment. They do, but the effect is of a lesser extent. Thus:

H3: When adding a healthy AFI to an unhealthy base packaged food, and this is presented in visual form (i.e., image), consumers perceive fewer food calories than that of the base food alone. When this healthy AFI is presented in a verbal form, the underestimation effect weakens. 


\section{STUDIES AND METHOD}

225

226

227

\section{Study 1 (A and B)}

This study tests the differences in consumers' calorie estimation when healthy AFI or unhealthy AFI are added to the packaging of a healthy or unhealthy packaged base food (see Table 1 for a summary of the experimental design). This study has two components, Study 1A and Study 1 B. In Study 1A, 232 students (123 male), age ranged 18 to $37(\mathrm{M}=24.05, \mathrm{SD}=2.98)$ were recruited in a marketing survey before the launching of a series of new packaged products. Two of the survey tasks were to estimate the calorie content and the perceived healthiness of the packaged food. Crisps and milk were chosen as the unhealthy and healthy base food respectively. The unhealthy characteristic of crisps and the healthy feature of milk are well documented in the literature (Adriaanse et al., 2009; Smith and Rogers 2014). We considered the use of a drink and a snack item as an acceptable compromise because of their very distinct and contrasting character (unhealthy versus healthy), their wide availability in packaged forms and high expected frequency of regular purchases so to secure respondent familiarity with the experimental contexts. Cucumber (as healthy) and BBQ (as unhealthy) AFIs for crisps were chosen followed by walnut (as healthy) and chocolate (as unhealthy) AFIs for milk, respectively. The participants were randomly assigned to a 2 (base food: healthy vs unhealthy) $\times 3$ (AFI: health vs unhealthy vs no AFI) betweensubjects design. Participants were first told to read the following cover story: 
good sales in snack/dairy market in recent years, and it is planning to launch a series of new flavour chips/milk to further enhance its market share. Before taking actions further, it hopes to know consumers'opinions about its new crisps/milk and the product packaging”.

Then, to decrease the variance caused by people's differences on calorie-content knowledge, a reference calorie content was provided to each participant with five filler questions. Specifically, after the introduction of cover story, participants in the healthy base food group were first shown the real product picture of a glass of raw milk, while those who were assigned to the unhealthy base food group were shown a plate of homemade crisps, attached with a description: "Below is the picture of the real product of a high rated homemade crisps/ raw milk in the market discovered by the marketing department of Cuello/Leit Leche"(See Appendix 1 for stimuli used in Study 1A). Then, they were asked to answer five filler questions, including 'the clarity of the picture', 'the attractiveness of the product', 'willingness to buy the displayed product', 'favored packaging style', and " $100 \mathrm{~g}$ of the homemade crisps contains $1300 \mathrm{KJ}$ calories or $250 \mathrm{ml}$ of the raw milk contains $700 \mathrm{KJ}$ calories, where would you think is most proper to present the calorie information $1300 \mathrm{KJ} / 100 \mathrm{~g}$ (or $700 \mathrm{KJ} / 250 \mathrm{ml}$ ) on the packaging?"

Next, participants entering into the focal study were told: "Below is a newly developed crisps/whole milk that Cuello/Leit Leche is about to launch", and were shown the front pack of either the packaged base food (i.e. the original crisps/milk), or the base packaged food with either the healthy or unhealthy AFI (i.e., with either the cucumber- or BBQ crisps, or the walnut- or chocolate whole milk. Each one of the four 
conditions was shown separately and no participant compared any two conditions together. They were then asked to answer four more filler questions on food attractiveness (three items: "the food is very tempting to me", "the food is very appealing to me", and "it would be very enjoyable if I ate this food; Cronbach's $\alpha=.86$ ), and clarity of pictures, as control variables. Finally, they were required to estimate the calories (According to your estimation, the calories of this flavored crisps/milk is.....KJ") and perceived healthiness (using seven-point Likert scale (1=very unhealthy, $7=$ very healthy). The used questionnaire is available in the web-appendix.

\section{Study 1A Results and Discussion}

Table 1 and Table 2 provide a summary of the results. Our manipulation check showed that, in the no AFI conditions (i.e., the packaged base food alone condition), participants perceived the whole milk as healthier (5.27 vs. the middle value $4, \mathrm{SD}=.69$, $\mathrm{t}(36)=11.15, p=.00)$, and perceived the crisps as unhealthier $(2.58$ vs. $4, \mathrm{SD}=.77, \mathrm{t}(35)=$ $-11.04, p=.00)$. Also, the difference between the healthiness perception of these two conditions was statistically significant $\left(\mathrm{F}(1,71)=245.83, p=.00, \eta^{2}=.78\right)$. An ANOVA revealed significant main effects on calorie estimation of base food $(F(1,226)=128.73$, $\left.p=.00, \eta^{2}=.36\right)$ and AFI $\left(\mathrm{F}(2,226)=28.15, p=.00, \eta^{2}=.20\right)$. The interaction effect between the base food and $\operatorname{AFI}\left(\mathrm{F}(2,226)=29.88, p=.00, \eta^{2}=.21\right)$ was also significant.

\section{<Insert here: Table 1 >}

<Insert here: Table 2 >

The contrast analysis shows that compared with presenting the unhealthy base food 
alone $(M=1331.94, S D=36.41)$, participants perceive lower calories when a healthy AFI is presented concurrently $\left(\mathrm{M}=1128.75, \mathrm{SD}=34.54, \mathrm{~F}(1,226)=15.89, p=.00, \eta^{2}=.13\right)$, while no significant change in calorie estimation was observed when an unhealthier AFI was presented $\left(\mathrm{M}=1413.95, \mathrm{SD}=186.05, \mathrm{~F}(1,72)=2.52, p=.12, \eta^{2}=.02\right)$. The healthiness perception increased significantly when adding a healthy AFI to a packaged unhealthy base food $(\mathrm{M}=3.63, \mathrm{SD}=.84)$, compared to that of the unhealthy base food alone $\left(\mathrm{M}=2.58, \mathrm{SD}=.77, \mathrm{~F}(1,226)=34.61, p=.00, \eta^{2}=.24\right)$. No significant differences in healthiness perception were observed between the conditions of adding an unhealthy AFI to an unhealthy base food (M=2.29, $\mathrm{SD}=.69)$, and of the unhealthy base food alone $\left(\mathrm{F}(1,226)=2.69, p=.10, \eta^{2}=.02\right)$.

Higher calorie estimates were observed in the healthy base food with an AFI condition than that of the healthy base food alone, no matter the AFI presented is healthy $\left(1044.19\right.$ vs $\left.710.27, \mathrm{~F}(1,226)=47.92, p=.00, \eta^{2}=.29\right)$ or unhealthy $(1142.11 \mathrm{vs}$ $\left.710.27, \mathrm{~F}(1,226)=75.55, p=.00, \eta^{2}=.40\right)$. Furthermore, compared to the healthy base food alone condition, adding an unhealthy AFI to a healthy base food lead to decreased healthiness perception significantly $\left(4.24\right.$ vs $\left.5.27, \mathrm{~F}(1,226)=75.55, p=.00, \eta^{2}=.40\right)$ and the perceived healthiness does not change significantly when presenting a healthy AFI on the packaging of a healthy base food (5.42 vs $\left.5.27, \mathrm{~F}(1,226)=.52, p=.47, \eta^{2}=.01\right)$.

To sum up, compared with the two control conditions (i.e., the healthy and unhealthy packed base food alone), a calorie underestimation effect was only observed in the combination of an unhealthy base and a healthy AFI among the four manipulated conditions (i.e., the 2 (AFI: healthy vs. unhealthy) $\times 2$ (packed base food: healthy vs. 
unhealthy)). A contrast on healthiness perception shows that adding a healthy AFI on the unhealthy packaged base food is accompanied with the most significant increase on perceived healthiness than the base food alone, in contrast to all other three manipulated conditions. This implies that, in principle, the enhanced healthiness perception is brought by the added healthy AFI to the augmented base food and leads to consumers' calorie underestimation.

However, a limitation in Study 1A is that the healthy and unhealthy base food belong to different categories (milk and crisps). Although the results generated from these common in daily consumption food items, provide valuable support to our hypotheses, the different nature of the categories (solid versus liquid) may confound the results. To provide a remedy, we conducted a post-hoc study (Study 1B) ( $n=163)$ (85 males, aged 17 to $29(\mathrm{M}=19.75, \mathrm{SD}=1.57)$ using a similar 2 (base food: healthy vs unhealthy) $\times 3$ (AFI: healthy vs unhealthy vs no AFI) between-subjects design which employs food items from the same solid food product category (snacks). These include healthy (apple chips) and unhealthy (potato crisps) as base foods; cinnamon and cucumber as healthy AFI, and BBQ as unhealthy AFI respectively (see appendix 2 for the stimuli of Study 1B). The rest of the procedure is the same as in study $1 \mathrm{~A}$.

\section{Study $1 B$ Results and Discussion}

The results of an ANOVA show significant main effects of base food $\left(\mathrm{F}(1,157)=266.97, p=.00, \eta^{2}=.63\right)$ and AFI $\left(\mathrm{F}(2,157)=3.95, p=.02, \eta^{2}=.05\right)$, and a significant interaction between food bases and AFI $\left(\mathrm{F}(2,157)=6.53, p=.02, \eta^{2}=.08\right)$ 
similar to our Study 1A findings. The contrast analysis shows that a lower calorie estimate is also repeatedly observed in the unhealthy base with a healthy AFI condition than that of the unhealthy base food alone (1088.40 vs $1295.83, \mathrm{~F}(1,157)=4.87, p=.03$ $\eta^{2}=.06$ ). There is no significant difference between the calorie estimate of the unhealthy base food with an unhealthy AFI and that of the base food alone (1382.14 vs 1295.83, $\left.\mathrm{F}(1,157)=.89, p=.35, \eta^{2}=.01\right)$. The calorie estimate of the healthy base food with AFI is higher than that of the healthy base food alone, regardless of whether the AFI is healthy (518.97 vs $\left.628.86, \mathrm{~F}(1,157)=5.44, p=.02, \eta^{2}=.06\right)$ or unhealthy (518.97 vs. 610.71 , $\left.\mathrm{F}(1,157)=3.72, p=.06, \eta^{2}=.04\right)$.

Moreover, we compared the perceived healthiness of food between different conditions. The contrast analysis shows that in the base food only conditions, participants perceived apple chips as healthy (5.28 vs. 4.0 the middle value, $t(29)=9.15$, $p=.00)$ and potato crisps as unhealthy ( 2.63 vs $4.0, \mathrm{t}(23)=-8.75, p=.00)$, and perceived the former to be healthier than the latter $\left(5.28\right.$ vs $\left.2.63, \mathrm{~F}(1,51)=159.98, p=.00, \eta^{2}=.76\right)$. Further contrasts show that a higher perceived healthiness of the augmented food (3.32 vs $\left.2.63, \mathrm{~F}(1,157)=11.08, p=.00, \eta^{2}=.17\right)$ was observed when adding a healthy AFI to the unhealthy base food, whereas no significant difference was found on the perceived healthiness ( 2.36 vs $\left.2.63, \mathrm{~F}(1,157)=1.74, p=.19, \eta^{2}=.02\right)$ when adding an unhealthy AFI. For healthy base food, a lower perceived healthiness was observed when adding an unhealthy topping ( 4.71 vs $5.28, \mathrm{~F}(1,157)=5.60, p=.02, \eta^{2}=.06$ ), and adding a healthy topping increased, albeit not statistically significantly, the perceived healthiness (5.59 vs $\left.5.28, \mathrm{~F}(1,157)=21.74, p=.19, \eta^{2}=.02\right)$. 

consistent either whether the comparison is between solid foods per se (potato vs apple crisps) or between a solid food (potato crisps) and a liquid (milk). These allow accepting Hla (when adding to a healthy base food either a healthy or an unhealthy AFI, consumer calorie estimation is higher than that of the base food alone). They also allow accepting $H I b$ (when adding to an unhealthy base food an unhealthy AFI, consumer calorie estimation is higher than that of the base food alone) and $H 1 c$ (when adding to an unhealthy base food a healthy AFI, consumer calorie estimation is lower than that of the base food alone).

\section{Study 2} underestimation effect occurring when adding a healthy AFI to an unhealthy base food

This study examines the underlying justification-related mechanism for (H2). 108 students (55 male, age ranged 17 to $27, \mathrm{M}=20.44, \mathrm{SD}=1.99$ ) were randomly assigned to a 2 (external justification: present vs absent) $\times 2$ (AFI: no AFI vs healthy AFI) between-subjects design. Like in Study 1, "Cuello" crisps were chosen as the stimuli and cucumber as AFI. Participants were firstly informed of a cover story similar to that in Study 1, i.e., we would like to learn their opinions regarding the packaging design of a new product concerning the given brand. Then the participants were shown the front pack of the original flavored "Cuello" crisps (See Appendix 3 for Study 2 stimuli) and were asked to complete the same questionnaire as in Study 1 and engaged with the referencing of the original crisps calories $(1300 \mathrm{KJ})$. Then, participants in the 
external justification present group were asked to vividly imagine the following three scenarios: (1) when they finished all their final exams with good marks; (2) when they were awarded scholarship at the beginning of a new semester because of their hard work in the previous semester; (3) when they received an internship offer from their dream company. This procedure aims to involve the participants in an external justification task (Khan and Dhar, 2006). Following, they were asked to choose among the three scenarios the one in which they were most likely to reward themselves with indulgent consumption. Next, they were asked to imagine that, under the chosen scenario, they went shopping and bought a bag of the new cucumber flavored Cuello crisps as a snack on a regular day (the same pictures as in Study 1 were used). Then each participant was asked to estimate the calories and the perceived healthiness. In the end, three questions were asked to test the extent to which each participant justifies their consumption, including "How much do you think you should reward yourself on that day?" "How much do you think you should treat yourself with delicious food on that day?" and "How much do you feel you deserve delicious food on that day?" $(0=$ not at all; $10=$ very much; Cronbach's alpha $=.82$ ). The factor scores averaged from these items were recorded as the external justification index.

\section{Study 2 Results and Discussion}

Manipulation checks show that participants in the external justification present group have higher justification scores than those in the justification absent group (6.91 vs $\left.4.83, \mathrm{~F}(1,106)=27.55, p=.00, \eta^{2}=.21\right)$. The ANOVA indicated a significant 
interaction effect between justification and AFI on calorie estimation $(F(1,104)=19.52$, $\left.p=.00, \eta^{2}=.16\right)$. The main effects of justification $\left(\mathrm{F}(1,104)=24.83, p=.00, \eta^{2}=.19\right)$ and AFI $\left(\mathrm{F}(1,104)=27.89, p=.00, \eta^{2}=.21\right)$ were also significant. Contrast tests indicate that, when external justification is absent, the calorie estimate of the unhealthy base food with healthy AFI is significantly lower than that of the food base food alone (1076.09 vs. $\left.1311.29, \mathrm{~F}(1,104)=47.33, p=.00, \eta^{2}=.31\right)$. When external justification is present, no significant difference is found regarding calorie estimates between the two respective ones $\left(1304.06\right.$ vs $\left.1325.00, \mathrm{~F}(1,104)=.37, p=.54, \eta^{2}=.004\right)$. The ANOVA on healthiness perception also depicted a significant main effect of justification $(F(1,104)=14.20$, $\left.p=.00, \eta^{2}=.12\right)$ and $\operatorname{AFI}\left(\mathrm{F}(1,104)=5.92, p=.02, \eta^{2}=.05\right)$, but the interaction between the two factors is not significant $\left(\mathrm{F}(1,104)=1.20, p=.28, \eta^{2}=.01\right)$. Higher healthiness perception were observed when there was no justification than when an external justification was provided (3.48 vs. $\left.2.83, \mathrm{~F}(1,104)=14.21, p=.00, \eta^{2}=.12\right)$. This result indicates that, in the absence of an external justification excuse, consumers deliberately to judge the unhealthy food to be healthier so that their indulgent consumption of the unhealthy food would be permitted. Supporting $H 2$, these results reveal that it is consumers' self-justification absence that, driving from the presence of healthy AFI, contributes to their calorie underestimation on the augmented unhealthy packaged food (see Table 1 and Table 2).

\section{Study 3}

This study tests whether the calorie underestimation effect when adding a healthy AFI 
on an unhealthy base food (Hlc) intensifies along increasing AFIs' perceived healthiness. Based on results of a pretest ${ }^{2}$ we identified that AFI stimuli with multiple different vegetables were perceived as healthier than a cucumber-alone AFI stimuli. Multiple different vegetables were also seen as a different condition but in essence multiplicative regarding perceived healthiness compared to multiple pieces of a single vegetable. Following, 87 students (45 male), age ranged 20 to $35(\mathrm{M}=24.56, \mathrm{SD}=2.47)$ attended a marketing survey involving a new packaged snack before launching, with two tasks: estimating snack's calories content and perceived healthiness when one healthy AFI (first manipulation) and when multiple different healthy AFIs were added (second manipulation) to the packaging of an unhealthy packaged base food (control condition). To maintain correspondence with Study 1, the control condition (i.e., crisps as unhealthy base food) stimuli and the first manipulation (i.e., crisps with cucumberalone) stimuli remained the same. The second manipulation used an AFI with five mixed vegetables (cucumber, tomato, eggplant, lettuce, and broccoli). The rationale is stimuli of Study 3).

\footnotetext{
227 students ( 12 male, $\mathrm{M}_{\mathrm{age}}=23.74, \mathrm{SD}=1.81$ ) attended the pre-test. They were invited to a marketing investigation about product packaging design before the launch of the new product "Cuello" crisps. Perceived healthiness was asked along with other three questions, including overall design of the packaging, the harmonious degree of the packaging, the clarity of the picture. ANOVA test show a significant effect of AFI on perceived healthiness $(\mathrm{F}(1,25)=4.64, p=.04)$. The "Cuello" crisps presented with an AFI consisting mixed vegetables was perceived healthier than that of the crisps with a cucumber-alone $\mathrm{AFI}\left(\mathrm{M}_{\text {mixed-vege }}=4.15, \mathrm{SD}=.99 ; \mathrm{M}_{\text {cucumber }}=3.43, \mathrm{SD}=.76\right)$.
} 
vs multiple different AFIs) ( $\mathrm{N}=29$ in each). Each one of conditions was shown separately and no participant compared any two conditions together. This study followed a procedure similar to Study 1: participants first read the cover story, were shown the real product picture of a homemade crisps and answered five filler questions, among which the reference calorie information was provided through the question " $100 \mathrm{~g}$ of the homemade crisps contains $1300 \mathrm{KJ}$ calories, where would you think is most proper to present the calorie information $1300 \mathrm{KJ} / 100 \mathrm{~g}$ on the packaging?" Next, participants were shown the front pack of either the original crisps, the cucumber crisps, or the mixed-vegetable crisps; three more filler questions were answered, followed by the estimation of the corresponding calories and healthiness perceptions.

\section{Study 3 Results and Discussion}

Manipulation check showed that compared with adding one healhty AFI (the cucumber condition), participants perceived the augmented unhealthy food that adding multiple AFIs to be healthier ( 3.52 vs. $\left.4.07, \mathrm{~F}(1,56)=4.84, p=.03, \eta^{2}=.08\right)$. ANOVA showed a significant effect of presenting type on calorie estimation $(F(2,84)=17.57$, $\left.p=.00, \eta^{2}=.30\right)$, as well as on healthiness perception $\left(\mathrm{F}(2,84)=14.17, \mathrm{p}=.00, \eta^{2}=.25\right)$.

The same effect as in Study 1 was shown, i.e. compared with the situation of the packed unhealthy base food alone, the perceived healthiness was enhanced in both healthy AFIs added conditions: in the cucumber AFI condition: $\mathrm{M}=3.52, \mathrm{SD}=.91$, vs $\mathrm{M}=2.76$, $\mathrm{SD}=.91, \mathrm{~F}(1,84)=9.42, p=.003, \eta^{2}=.10$ and in the healthier mixed-vegetable AFI condition: $\left.\mathrm{M}=4.07, \mathrm{SD}=1.00, \mathrm{~F}(1,84)=28.10, p=.00, \eta^{2}=.25\right)$. Participants also 
perceived the augmented crisps with the mixed-vegetable AFI as healthier than the augmented crisps with the cucumber AFI $\left(\mathrm{F}(1,84)=4.98, p=.03, \eta^{2}=.06\right)$. In concordance with Study 1 findings, participants estimated fewer (and quite similar to Study 1 figures) calorie content on the augmented packaged food when a cucumberalone healthy AFI was added $(\mathrm{M}=1179.31, \mathrm{SD}=161.20)$ than the base food alone $\left(\mathrm{M}=1318.97, \mathrm{SD}=201.52, \mathrm{~F}(1,84)=10.49, p=.002, \eta^{2}=.11\right)$. Importantly, participants perceive the unhealthy augmented packaged food with the more pronounced 'healthier' vegetable-mix AFI as having the least calories $(\mathrm{M}=1063.79, \mathrm{SD}=119.45, \mathrm{~F}(1$, $\left.84)=35.03, p=.00, \eta^{2}=.29\right)$. Between the two healthy AFI manipulations, the mixedvegetable condition was estimated as having significantly fewer calories than the cucumber-alone condition $\left(\mathrm{F}(1,84)=7.18, p=.009, \eta^{2}=.08\right)$.

Study 3's outcomes are consistent with Study 1's outcomes confirming the initial findings. $H 1 c$ acceptance is repeated again, and the findings clarify that the calorie underestimation effect when a healthy AFI is added on an unhealthy packaged based food is a function of the strength of the perceived healthiness of the augmented food. The calorie underestimation is intensified along a strengthened healthiness perception of the AFI.

\section{Study 4}

This study tests the boundary effect of AFI forms (visual vs verbal) on unhealthy food calorie estimates and considers explicitly if the verbal effects mitigate the underestimation effect evident in the former studies. 127 students (65 male) (aged 
$\mathrm{M}=24.97, \mathrm{SD}=2.58$ ) attended a marketing survey involving a new packaged snack before launching, with two of the tasks designed as estimating the snack's calories content and perceived healthiness. To generalize and expand on the previous results, the pictorial representation of Maryla (a made-up brand which differs from that of the previous studies) cookies were introduced as stimuli. Cookies without an AFI reflect the control condition (unhealthy base food alone). Cookies with strawberry reflect an unhealthy base food + healthy AFI and two manipulations were developed: the first has the picture of strawberry (i.e., a visual condition) as AFI and the second has the text 'strawberry' on the packaging (a verbal condition) as AFI (with approximately similar size as the picture). To note that the small chips on the cookies are strawberry chips. Participants were randomly assigned to one of these three conditions. Study 1's procedure was replicated here excerpt changing the brand name in the cover story as "Maryla". After reading the cover story, participants were shown the picture of a plate of referenced cookies (See Appendix 5 for the stimuli of Study 4). They were next asked to complete five filler questions, including " $100 \mathrm{~g}$ of the handmade cookies contains $2200 \mathrm{KJ}$ calories, where would you think is most proper to present the calorie information $2200 \mathrm{KJ} / 100 \mathrm{~g}$ on the packaging?" to provide them with referencing calorie information. The participants were later shown the front pack of packaged cookies (containing six grab bags), either of the original flavour or strawberry flavour. Each one of conditions was shown separately and no participant compared any two conditions together. They were then asked to answer two questions relating attention, including "the flavor of the cookies" and "how clear do you think the packaging informed that 
the product it contains". Then, four more filler questions, as well as to estimate the calorie content and perceived healthiness of the new product. The filler questions included the food attractiveness (three items, Cronbach's $\alpha=0.88$ ), the clarity of the pictures, the harmony of the package design, the overall evaluation of the design of the packaging. As a check on the effect of the AFI on consumers' purchase behavior, participants were also asked to report "to what extent are you tempting to purchase this cookie".

\section{Study 4 Results and Discussion}

Manipulation check shows that all participants correctly answered the flavor of the cookies used in their participated condition. Moreover, an ANOVA test informed no significant differences among three conditions on packaging's informing mode $\left(\mathrm{F}(2,124)=.02, p=.985, \eta^{2}=.0\right)$. This result rules out the explanation that the calories underestimation effect in visual AFI condition is due to different consumer attention generated by visual $v s$ verbal AFIs presented on the packaging of base food.

An ANOVA shows that the presenting format of healthy AFI on the packed unhealthy base food has a significant impact on the calorie underestimation effect $(\mathrm{F}(2$, 124)=7.89, $p=.00, \eta^{2}=.11$ ). For the same unhealthy base food, consumers' calorie estimate with healthy AFI presented in pictures $(\mathrm{M}=2024.42, \mathrm{SD}=267.57)$ was lower than those under conditions of healthy AFI presented in words (M=2157.14, $\mathrm{SD}=175.50)$ and the control no-AFI condition $(M=2208.33, \mathrm{SD}=207.46)$. The underestimation effect is statistically significant when the healthy AFI is presented in 
the picture on the packaging than there is no AFI added $(\mathrm{F}(1,124)=14.77, p=.00$, $\eta^{2}=.11$ ). In contrast, no statistically significant difference was found between the estimated calories of presenting healthy AFI in words than the no AFI condition ( $\mathrm{F}(1$, 124) $\left.=1.13, p=.29, \eta^{2}=.01\right)$.

Differences in the perceived product healthiness are also observed among the three studied conditions $\left(\mathrm{M}_{\mathrm{AFI}}\right.$ in picture=3.70 vs $\mathrm{M}_{\mathrm{no}} \mathrm{AFI}=3.05$ vs $\mathrm{M}_{\mathrm{AFI}}$ in words $=3.19, \mathrm{~F}(2$, 124) $\left.=5.74, p=.004, \eta^{2}=.09\right)$. Respondents perceive the augmented unhealthy food to be healthier when there is a healthy AFI presented in picture format on the packaging than the base food alone, and the difference is statistically significant $((\mathrm{F}(1,124)=10.36$, $\left.p=.002, \eta^{2}=.08\right)$. However, no statistically significant differences were found in the perceived healthiness between the condition of presenting the AFI in words on the packaging and the base food alone $\left(\mathrm{F}(1,124)=.50 \cdot p=.48, \eta^{2}=.004\right)$. These findings lend support to accept $H 3$ suggesting that the presentation form of AFI is a boundary for our focus underestimation effect. The findings demonstrate that the calorie underestimation effect retains its strength when the healthy AFI is presented in pictures on the packaging of an unhealthy base food but weakens (albeit not disappearing) when the AFI is presented in words.

An additional ANOVA shows that the AFI has a significant effect on consumers' purchase intention $\left(\mathrm{F}(2,124)=3.46, p=.04, \eta^{2}=.05\right)$. Further contrast shows that, compared with the no AFI condition ( $\mathrm{M}=4.12, \mathrm{SD}=1.17)$, participants are tempted to purchase the cookies when presenting the AFI in picture $(\mathrm{M}=4.77, \mathrm{SD}=1.36 ; \mathrm{F}(1$, $\left.124)=5.54, p=.02, \eta^{2}=.04\right)$, but no significant difference is observed when the AFI is 
presented verbally $\left(\mathrm{M}=4.17, \mathrm{SD}=1.27 ; \mathrm{F}(1,124)=.03, p=.86, \eta^{2}=.00\right)$.

\section{General discussion}

Overview of the findings

The current research explores the impact of AFIs presented on packaged foods on consumers' estimates of food calories and perceived healthiness. Its differentiating 
justification or the AFI is in verbal form but it increases further if its visual form involves multiple healthy ingredients. Study 1 shows that among the studied combinations, the healthy (visual) AFI/unhealthy packaged base food leads to harmful for the consumers results; this also occurs irrespectively of the solid or liquid nature of the food product. We theorize complementing previous literature that a health-heuristic is triggered to help consumers justify the indulgent and health harmful purchase. These interface with consumers' motivation for justification, precluding them from a hedonism-gratification excuse. Study 2 demonstrates that when an external justification excuse is present, the effect is indeed no longer produced. Study 3 and 4 provide evidence on the functioning of the effect. In Study 3 , when the presented visual healthy AFI expands from involving only one (cucumber) to involving many (mixed, comprising five different vegetables), the effect increases even further but the effect is weakened as shown in Study 4 when the AFI presented in verbal form. Comparing with visual cues, verbal cues activate but they have as diagnostic heuristics a lesser effect.

As AFIs exert critical influence over consumer judgment as inferential cues, our work also provides best marketing practice regarding broadening product lines (e.g., Bayus and Putsis, 1999) and especially product line optimization (e.g., Netessine and Taylor, 2007) based on ethical and obesity prevention grounds.

\section{Implications}

Our research has implications for consumers, food enterprises, and policy makers.

First, our findings suggest that consumers should be cautious of the judgment bias 
caused by the presence of an AFI on food packages, and raise their awareness regarding nutrition implications and dietary effects. Packaged food with AFI are widespread and consumers should be alerted of this biased judgment regarding the healthiness nature of food, incorrect food calorie estimates, and erroneous calorie intake monitoring, so they may not make informed purchase decisions that are consistent with their expectations. Experts (like nutritionists and dieticians) should be alerted to the conditions that generate how consumers become self-misled.

From the perspective of food manufacturers though, adding healthy AFI to unhealthy base foods although may increase consumers' purchase intention and bring higher profits, may not be sustainable as a marketing strategy in the long-term and has immediate ethical implications. Self-misled consumers' purchases through seemly healthier food combinations instigates self-harm, damages consumers' own interests and raises important ethical concerns and questions who consumers may blame later.

Future consumer reactions may lead to potential consumer blame-shifting away from themselves and rejection of manufacturing/branding practices in the first instance. Consumer reasoning may well be based on their own claims regarding industry versus consumer power and knowledge imbalance, the consumers been self-seen as weaker and less-knowledgeable. Reaching such a point may jeopardize not only consumer loyalty, but increase mistrust and hurt brand (and product range) profits.

On the other hand, food enterprises can improve the promotion and sales of healthy food by taking appropriate advantage of AFIs. Our work allows to suggest that food enterprises can consolidate considerations on both sides of the firm's short-term profit 
and public health, when they choose and present AFI in a way that minimizes consumer bias and help consumers make healthier purchases. In branding and communication, external justifications may be used as part of firms' communication strategy and an explanation of the mechanism in operation. Transparency and explanation will not harm either product/brand perceptions or profits. Consumers will likely reward such firms, and their loyalty will increase as further trust is established in the food enterprises who substantiate that they have consumers' interests at heart.

Finally, policymakers could introduce voluntary schemes to monitor and restrict the improper presentation of AFIs, aiming to rule out the abuse of healthy AFIs on unhealthy packaged food. Other relevant organizations could also endeavor to promote consumer awareness of the biased impacts of AFI on consumer judgment and decisionmaking.

\section{Limitations and Future Research}

Further research should test across the broader range of the food product matrix. Though we consider the condition of one vs multiple AFI types, we do not examine specific numerical thresholds nor what happens in a likely intermediate condition (i.e., multiple pieces of a single vegetable). Our research focuses on the most common (namely, AFI on the packaging of packaged food) but such AFIs may be elusive. There is a great diversity of AFI presentations. For instance, in the common combination of cookies and milk, the cookies and milk can be treated as AFI for each other. In other cases, there are AFI presented for decoration only, such as the cinnamon 
638

639

640

641

642

643

644

645

646

647

648

649

650

651

652

653

654

655

656

657

658

659

660

stick in an ice cream cone. Further research may deal with the impact of AFI of these different forms on consumers' calorie estimation and healthiness perceptions.

Future research may also test further additional sensory-arousing mechanisms that can help understand how consumer perceive the calories of the augmented food. The shape, colour, and the imagery of package, among other things, can arouse the sense of taste (Piqueras-Fiszman et al., 2012; Spence, 2012). In our cucumber crisps, the calorie underestimation effect may relate to an expected healthy taste or smell sense aroused by the green colour of the cucumber presented on the package of the crisps. People may also associate certain shapes with relevant food tastes (Spence and Gallace, 2011). Irregular rectangles are associated with dark chocolate in a higher percentage of cocoa (bitter), roundness shapes with milk chocolate (much sweeter), and rectangles with cranberry juice (sour). Moreover, future research may consider introducing eyetracking experiments as an alternative instrument to explore the AFI phenomenon. Adding functional type ingredients may be another area for further research. AFIs are added to products such as detergents, essential oils, and air fresheners (e.g., typical AFIs for detergent include ginger, lemon, and kumquat). It is likely that, consumers would think the products are more natural and mild to the skin when more healthy AFIs are added.

\section{References}

Adriaanse, M.A., de Ridder, D.T.and de Wit, J.B. (2009), Finding the critical cue: implementation intentions to change one's diet work best when tailored to personally relevant reasons for unhealthy eating. Personality and Social Psychology Bulletin, 
35(1), 60-71.

Alesandrini, K.L.and Sheikh, A. (1983), Research on imagery: applications of advertising. In Imagery: current theory and applications. Sheikh, A. (Ed), New York: John Wiley and Sons, 535-556.

Aydinoğlu, N.Z. and Krishna, A. (2011), Guiltless gluttony: The asymmetric effect of size labels on size perceptions and consumption. Journal of Consumer Research, 37(6), 1095-1112.

Bayus, B.L. and Putsis, W.P. (1999), Product proliferation: An empirical analysis of product line determinants and market outcomes. Marketing Science, 18.2:137-153.

Bazerman, M.H. (2001), Consumer research for consumers. Journal of Consumer Research, 27(4), 499-504.

Becker, M.W., Bello, N.M., Sundar, R.P., Peltier, C.and Bix, L. (2015), Front of pack labels enhance attention to nutrition information in novel and commercial brands. Food Policy, 56, 76-86.

Carr, T.H., McCauley, C., Sperber, R.D.and Parmelee, C.M. (1982), Words, pictures and priming: on semantic activation, conscious identification and the automaticity of information processing. Journal of Experimental Psychology: Human Perception and Performance, 8(6), 757.

Chaiken, S. (1980), Heuristic versus systematic information processing and the use of source versus message cues in persuasion. Journal of Personality and Social Psychology, 39, 752-766.

Chaiken, S. and Eagly, A.H. (1989), Heuristic and systematic information processing within and beyond the persuasion context. Unintended Thought, 212-252.

Chandon P.and Wansink B. (2007), The biasing health halos of fast-food restaurant health claims: lower calorie estimates and higher side-dish consumption intentions. Journal of Consumer Research, 34, 301-314.

Cheema, A., \& Soman, D. (2006). Malleable mental accounting: the effect of flexibility on the justification of attractive spending and consumption decisions. Journal of Consumer Psychology, 16(1), 33-44

Chen, S., Duckworth, K.and Chaiken, S. (1999), Motivated heuristic and systematic 
processing. Psychological Inquiry, 10(1), 44-49.

Chernev, A. and Gal, D. (2010), Categorization effects in value judgments: Averaging bias in evaluating combinations of vices and virtues. Journal of Marketing Research, 47, $738-747$.

Chernev, A. (2011a). The dieter's paradox. Journal of Consumer Psychology, 21(2), 178183.

De Pelsmacker, P., Geuens, M.and Van den Bergh J. (2011), Marketing-communicatie (5 $5^{\text {th }}$ $E d$ ), Pearson Education NL.

Deng, X.and Srinivasan, R. (2013), When do transparent packages increase (or decrease) food consumption? Journal of Marketing, 77, 104-117.

Desai, P. S. (2001), Quality segmentation in spatial markets: When does cannibalization affect product line design? Marketing Science, 20.3, 265-283.

Draganska, M., \& Jain, D. C. (2006). Consumer preferences and product-line pricing strategies: An empirical analysis. Marketing science, 25(2), 164-174.

Eagly, A.H. and Chaiken, S. (1993), The psychology of attitudes. Harcourt Brace Jovanovich College Publishers.

Fishbach, A., Friedman, R.S. and Kruglanski, A.W. (2003), Leading us not into temptation: Momentary allurements elicit overriding goal activation. Journal of Personality and Social Psychology, 84 (2), 296-309.

Giner-Sorolla, R. (2001), Guilty pleasures and grim necessities: Affective attitudes in dilemmas of self-control. Journal of Personality and Social Psychology, 80 (2), 206221.

Haytowitz, D.B. and Pehrsson P.R. (2018), USDA's national food and nutrient analysis program (NFNAP) produces high-quality data for USDA food composition databases: Two decades of collaboration. Food Chemistry, 238, 134-138

Houston, M.J., Childers, T.L. and Heckler, S.E. (1987), Picture-word consistency and the elaborative processing of advertisements. Journal of Marketing Research, 359-369.

Hsee, C. K. (1995), Elastic justification: How tempting but task-irrelevant factors influence decisions. Organizational Behavior and Human Decision Processes, 62(3), 330-337. 
Hsee, C. K. (1996), Elastic Justification: How Unjustifiable Factors Influence Judgments. Organizational Behavior and Human Decision Processes, 66(1), 122-129.

Jiang, Y. and Lei, J. (2014), The effect of food toppings on calorie estimation and consumption. Journal of Consumer Psychology, 24, 63-69.

Kang, W. and Montoya, M. (2014), The impact of product portfolio strategy on financial performance: The roles of product development and market entry decisions. Journal of Product Innovation Management, 31(3), 516-534.

Kisielius, J. and Sternthal, B. (1986). Examining the vividness controversy: An availability-valence interpretation. Journal of Consumer Research, 12(4), 418-431.

Kivetz, R. and Simonson, I. (2002), Earning the right to indulge: Effort as a determinant of customer preferences toward frequency program rewards. Journal of Marketing Research, 39(2), 155-170.

Koo, M. and Fishbach, A. (2008), Dynamics of self-regulation: How (un)accomplished goal actions affect motivation. Journal of Personality and Social Psychology, 94(2), 183-195.

Kozup, J.C., Creyer, E.H. and Burton, S. (2003), Making healthful food choices: the influence of health claims and nutrition information on consumers' evaluations of packaged food products and restaurant menu items. Journal of Marketing, 67(2), 1934.

Kunda, Z., (1990), The case for motivated reasoning. Psychological Bulletin, 108(3), 480-498.

MacInnis D.J. and Price L.L. (1987), The role of imagery in information processing: Review and extensions. Journal of Consumer Research, 13, 473-491.

Madzharov, A.V. and Block, L.G. (2010), Effects of product unit image on consumption of snack foods. Journal of Consumer Psychology, 20, 398-409.

McClure, S.M., Botvinick, M.M., Yeung, N., Greene, J.D. and Cohen, J.D. (2007), Conflict monitoring in cognition-emotion competition. Handbook of Emotion Regulation. 204-226.

McFadden, D. (2001), Economic choices. American Economic Review, 91(3), 351-378. Netessine, S. and Taylor, T.A. (2007), Product line design and production technology. 
Marketing Science, 26(1), 101-117.

752

Okada, E.M. (2005), Justification effects on consumer choice of hedonic and utilitarian goods. Journal of Marketing Research, 42(1), 43-53.

Piqueras-Fiszman, B., Alcaide, J., Roura, E. and Spence, C. (2012), Is it the plate or is it the food? Assessing the influence of the color (black or white) and shape of the plate on the perception of the food placed on it. Food Quality and Preference, 24(1), 205208.

Prelec, D. and Loewenstein, G. (1998), The red and the black: Mental accounting of savings and debt. Marketing Science, 17(1), 4-28.

Raghubir, P. and Krishna, A. (1999), Vital dimensions in volume perception: can the eye fool the stomach? Journal of Marketing Research, 36, 313-326.

Raghunathan, R., Naylor, R. W. and Hoyer, W. D. (2006), The unhealthy tasty intuition and its effects on taste inferences, enjoyment and choice of food products. Journal of Marketing, 70(4), 170-184.

Randall, T., Ulrich, K. and Reibstein, D. (1998), Brand equity and vertical product line extent. Marketing Science, 17.4:356-379.

Rebollar, R., Gil, I., Lidón, I., Martín, J., Fernández, M.J. and Rivera, S. (2017), How material, visual and verbal cues on packaging influence consumer expectations and willingness to buy: The case of crisps (potato chips) in Spain. Food Research International, 99, 239-246

Roe, M., Pinchen, H., Church, S. and Finglas, P. (2015), McCance and Widdowson's the composition of foods: Seventh summary edition and updated composition of foods integrated dataset. Nutrition Bulletin, 40(1), 36-39.

Scheibehenne, B., Miesler, L. and Todd, P.M. (2007), Fast and frugal food choices: Uncovering individual decision heuristics. Appetite. 49(3), pp.578-589.

Schulte-Mecklenbeck, M., Sohn, M., De Bellis, E., Martin, N., and Hertwig, R. (2013), A lack of appetite for information and computation. Simple heuristics in food choice. Appetite, 71, 242-251.

Sevilla, J. and Kahn, B.E. (2014), The completeness heuristic: Product shape completeness influences size perceptions, preference and consumption. Journal of 
Marketing Research, 51, 57-68.

Shiv, B. and Fedorikhin, A. (1999), Heart and mind in conflict: The interplay of affect and cognition in consumer decision making. Journal of Consumer Research, 26(3), 278-292.

Silayoi, P. and Speece, M. (2004), Packaging and purchase decisions: An exploratory study of the impact of involvement and time pressure. British Food Journal, 106(8), 607-628

Silayoi, P. and Speece, M. (2007), The importance of packaging attributes: a conjoint analysis approach. European Journal of Marketing, 41 (11/12), 1495-517.

Smith, A.P. and Rogers, R. (2014), Positive effects of a healthy snack (fruit) versus an unhealthy snack (chocolate/crisps) on subjective reports of mental and physical health: a preliminary intervention study. Frontiers in nutrition. 1, 10

Spence, C. (2012), Managing sensory expectations concerning products and brands: Capitalizing on the potential of sound and shape symbolism. Journal of Consumer Psychology, 22(1), 37-54.

Spence, C. and Gallace, A. (2011), Multisensory design: Reaching out to touch the consumer. Psychology and Marketing. 28(3), 267-308.

Strahilevitz, M. and Myers, J.G. (1998), Donations to charity as purchase incentives: How well they work may depend on what you are trying to sell. Journal of Consumer Research, 24(4), 434-446.

Swinburn, B., Kraak,V., Rutter, H., Vandevijvere, S., Lobstein, T., Sacks, G., Gomes, F., Marsh, T. and Magnusson, R. (2015), Strengthening of accountability systems to create healthy food environments and reduce global obesity. The Lancet, 385(9986): 2534-2545.

Tversky, A. and Kahneman, D. (1973), Availability: A heuristic for judging frequency and probability. Cognitive Psychology, 5, 207-232.

Underwood, R.L., Klein, N.M. and Burke, R.R. (2001), Packaging communication: attentional effects of product imagery. Journal of Product and Brand Management, 10(7), 403-422.

Underwood, R.L. and Klein, N.M. (2002), Packaging as brand communication: effects of 
product pictures on consumer responses to the package and brand. Journal of Marketing Theory and Practice. 10, 58-68.

Van Oseelaer, S.M.I. (2008), Associate learning and consumer decisions in Haugtvedt, C. P., Herr, P. M., Kardes F. R. (Eds). Handbook of Consumer Psychology. New York: Taylor and Francis, 699-732.

Wansink, B. and Chandon, P. (2006), Can "low-fat" nutrition labels lead to obesity? Journal of Marketing Research, 43(4), 605-617.

Wansink, B., Sonka, S.T. and Hasler, C.M. (2004), Front-label health claims: when less is more. Food Policy, 29(6), 659-667.

Wertenbroch, K. (1998), Consumption self-control by rationing purchase quantities of virtue and vice. Marketing Science, 17, 317-337.

Wilder, L.B., Cheskin, L.J. and Margolis S. (2007), Nutrition and weight control for longevity. Johns Hopkins Health.

$\mathrm{Xu}$, J. and Schwarz, N. (2009), Do we really need a reason to indulge? Journal of Marketing Research, 46(1), 25-36. 
Table 1: Experimental Design and Score Means (Standard Deviations)

\begin{tabular}{|c|c|c|c|c|c|c|c|}
\hline Study & Variable & & & Scores & & & \\
\hline \multirow[t]{3}{*}{$\mathbf{1 A}$} & & Solid Unhealthy Base & $\begin{array}{c}\text { Solid Unhealthy Base } \\
\text { + Healthy AFI }\end{array}$ & $\begin{array}{c}\text { Solid Unhealthy Base } \\
\text { + Unhealthy AFI }\end{array}$ & $\begin{array}{c}\text { Liquid Healthy } \\
\text { Base }\end{array}$ & $\begin{array}{l}\text { Liquid Healthy Base } \\
\text { + Healthy AFI }\end{array}$ & $\begin{array}{c}\text { Liquid Healthy Base } \\
\text { + Unhealthy AFI }\end{array}$ \\
\hline & Calorie Estimation & $1331.94(244.12)$ & $1128.75(232.02)$ & $1413.95(186.05)$ & $710.27(155.68)$ & $1044.19(249.34)$ & $1142.11(222.86)$ \\
\hline & Healthiness perception & $2.58(.77)$ & $3.63(.84)$ & $2.29(.69)$ & $5.27(.69)$ & $5.42(.96)$ & $4.24(1.05)$ \\
\hline \multirow[t]{3}{*}{ 1B } & & Same As Above & Same As Above & Same As Above & Solid Healthy Base & $\begin{array}{l}\text { Solid Healthy Base } \\
\text { + Healthy AFI }\end{array}$ & $\begin{array}{l}\text { Solid Healthy Base } \\
\text { + Unhealthy AFI }\end{array}$ \\
\hline & Calorie Estimation & $1295.83(338.13)$ & $1088.40(242.79)$ & 1382.14(383.02) & $518.97(161.70)$ & $628.86(210.60)$ & $610.71(160.65)$ \\
\hline & Healthiness perception & $2.63(0.77)$ & $3.32(0.80)$ & $2.36(0.62)$ & $5.28(0.75)$ & $5.59(0.83)$ & $4.71(1.08)$ \\
\hline \multirow[t]{3}{*}{2} & & $\begin{array}{c}\text { Solid Unhealthy Base } \\
+ \text { Present External } \\
\text { Justification }\end{array}$ & $\begin{array}{c}\text { Solid Unhealthy Base } \\
+ \text { Absent External } \\
\text { Justification }\end{array}$ & $\begin{array}{c}\text { Solid Unhealthy Base } \\
\text { +Healthy AFI } \\
\text { + Present External } \\
\text { Justification }\end{array}$ & $\begin{array}{c}\text { Solid Unhealthy } \\
\text { Base +Healthy AFI } \\
\text { + Absent External } \\
\text { Justification }\end{array}$ & & \\
\hline & Calorie Estimation & $1325.00(119.27)$ & $1311.29(145.89)$ & $1304.06(99.73)$ & $1076.09(127.81)$ & & \\
\hline & Healthiness perception & $2.68(1.00)$ & $3.19(.79)$ & $2.94(1.13)$ & $3.87(.97)$ & & \\
\hline \multirow[t]{3}{*}{3} & & Solid Unhealthy Base & $\begin{array}{c}\text { Solid Unhealthy Base } \\
\text { + One AFI }\end{array}$ & $\begin{array}{l}\text { Solid Unhealthy Base } \\
\text { + Multiple AFIs }\end{array}$ & & & \\
\hline & Calorie Estimation & $1318.97(201.52)$ & $1179.31(161.20)$ & 1063.79 (119.45) & & & \\
\hline & Healthiness perception & $2.76(.91)$ & $3.52(.91)$ & $4.07(1.0)$ & & & \\
\hline \multirow[t]{3}{*}{4} & & Solid Unhealthy Base & $\begin{array}{c}\text { Solid Unhealthy Base } \\
\text { + AFI in pictures }\end{array}$ & $\begin{array}{c}\text { Solid Unhealthy Base } \\
\text { + AFI in text }\end{array}$ & & & \\
\hline & Calorie Estimation & $2208.33(207.46)$ & $2024.42(267.57)$ & $2157.14(175.50)$ & & & \\
\hline & Healthiness perception & $3.05(1.08)$ & $3.70(.89)$ & $3.19(.80)$ & & & \\
\hline
\end{tabular}


Table 2: ANOVA Results

\begin{tabular}{|c|c|c|c|c|c|c|c|c|c|c|c|c|c|c|c|c|}
\hline \multirow[t]{2}{*}{ Study } & \multirow[t]{2}{*}{ Variable } & \multicolumn{3}{|c|}{$\begin{array}{l}\text { Overall* }^{*} \\
\text { IV: Base }\end{array}$} & \multicolumn{3}{|c|}{$\begin{array}{l}\text { Overall }^{*} \\
\text { IV: AFI }\end{array}$} & \multicolumn{3}{|c|}{ Overall $^{*}$} & \multicolumn{3}{|c|}{$\begin{array}{c}\text { Unhealthy Base } \\
\text { IV: AFI }\end{array}$} & \multicolumn{3}{|c|}{$\begin{array}{c}\text { Healthy Base } \\
\text { IV: AFI }\end{array}$} \\
\hline & & $\mathbf{F}(\mathbf{1})$ & $p(\mathbf{1})$ & $\eta^{2}(1)$ & $\mathbf{F}(2)$ & $p(2)$ & $\eta^{2}(2)$ & $\mathbf{F}(3)$ & $p(3)$ & $\eta^{2}(3)$ & $\mathbf{F}(4)$ & $p(4)$ & $\eta^{2}(4)$ & $\mathbf{F}(\mathbf{5})$ & $p(5)$ & $\eta^{2}(5)$ \\
\hline \multirow[t]{4}{*}{$\mathbf{1 A}$} & Calorie Estimation & 128.73 & .00 & .36 & 28.15 & .00 & .20 & 29.88 & .00 & .20 & 17.13 & .00 & .24 & 41.69 & .00 & .42 \\
\hline & Healthiness perception & 368.93 & .00 & .62 & 43.66 & .00 & .28 & 6.00 & .00 & .05 & 32.42 & .00 & .37 & 19.26 & .00 & .25 \\
\hline & & \multicolumn{3}{|c|}{ Overall $^{*}$} & \multicolumn{3}{|c|}{ Overall* $^{*}$} & \multicolumn{3}{|c|}{ Overall* $^{*}$} & \multicolumn{3}{|c|}{ Unhealthy Base } & \multicolumn{3}{|c|}{ Healthy Base } \\
\hline & & \multicolumn{3}{|c|}{ IV: Base } & \multicolumn{3}{|c|}{ IV: AFI } & \multicolumn{3}{|c|}{ IV: Base $\times$ AFI } & \multicolumn{3}{|c|}{ IV: AFI } & \multicolumn{3}{|c|}{ IV: AFI } \\
\hline \multirow{3}{*}{ 1B } & & $\mathbf{F}(\mathbf{6})$ & $p(6)$ & $\eta^{2}(6)$ & $\mathbf{F}(7)$ & $p(7)$ & $\eta^{2}(\mathbf{8})$ & $\mathbf{F}(9)$ & $p(9)$ & $\eta^{2}(9)$ & $\mathbf{F}(10)$ & $p(10)$ & $\eta^{2}(10)$ & $\mathbf{F}(11)$ & $p(11)$ & $\eta^{2}(11)$ \\
\hline & Calorie Estimation & 266.97 & .00 & .63 & 3.95 & .21 & .05 & 6.53 & .00 & .08 & 5.48 & .01 & .13 & .31 & .049 & .07 \\
\hline & Healthiness perception & 352.82 & .00 & .69 & 17.11 & .00 & .18 & .79 & .45 & .01 & 12.01 & .00 & .25 & 6.92 & .002 & .14 \\
\hline \multirow[t]{5}{*}{2} & & \multicolumn{3}{|c|}{ Unhealthy Base } & \multicolumn{3}{|c|}{ Unhealthy Base } & \multicolumn{3}{|c|}{ Unhealthy Base } & \multirow{2}{*}{\multicolumn{3}{|c|}{$\begin{array}{l}\text { Justification Absent } \\
\text { IV: AFI }\end{array}$}} & \multirow{2}{*}{\multicolumn{3}{|c|}{$\begin{array}{c}\text { Justification Present } \\
\text { IV: AFI }\end{array}$}} \\
\hline & & \multicolumn{3}{|c|}{ IV: Justification } & \multicolumn{3}{|c|}{ IV: AFI } & \multicolumn{3}{|c|}{ IV: Justification $\times$ AFI } & & & & & & \\
\hline & & $\mathbf{F}(12)$ & $p(12)$ & $\eta^{2}(12)$ & $F(7)$ & $p(7)$ & $\eta^{2}(\mathbf{8})$ & $\mathbf{F}(9)$ & $p(9)$ & $\eta^{2}(9)$ & $\mathbf{F}(\mathbf{1 0})$ & $p(\mathbf{1 0})$ & $\eta^{2}(10)$ & $\mathbf{F}(\mathbf{1 1})$ & $p(11)$ & $\eta^{2}(11)$ \\
\hline & Calorie Estimation & 24.83 & .00 & .19 & 27.89 & .00 & .21 & 19.52 & .00 & .16 & 38.06 & .00 & .42 & .49 & .49 & .01 \\
\hline & Healthiness perception & 14.20 & .00 & .12 & 5.92 & .02 & .05 & 1.20 & .28 & .01 & 7.95 & .01 & .13 & .73 & .40 & .01 \\
\hline 3 & & & healthy $B$ & & & & & & & & & & & & & \\
\hline & & & AFI (var) & & & & & & & & & & & & & \\
\hline & & $\mathbf{F}(12)$ & $p(12)$ & $\eta^{2}(12)$ & & & & & & & & & & & & \\
\hline & Calorie Estimation & $\mathbf{1 7 . 5 7}$ & .00 & .30 & & & & & & & & & & & & \\
\hline & Healthiness perception & 14.17 & .00 & .25 & & & & & & & & & & & & \\
\hline 4 & & & healthy $B$ & & & & & & & & & & & & & \\
\hline & & IV: AFI & presentin & ormat) & & & & & & & & & & & & \\
\hline & & $F(13)$ & $p(13)$ & $\eta^{2}(13)$ & & & & & & & & & & & & \\
\hline & Calorie Estimation & 7.89 & .00 & .11 & & & & & & & & & & & & \\
\hline
\end{tabular}




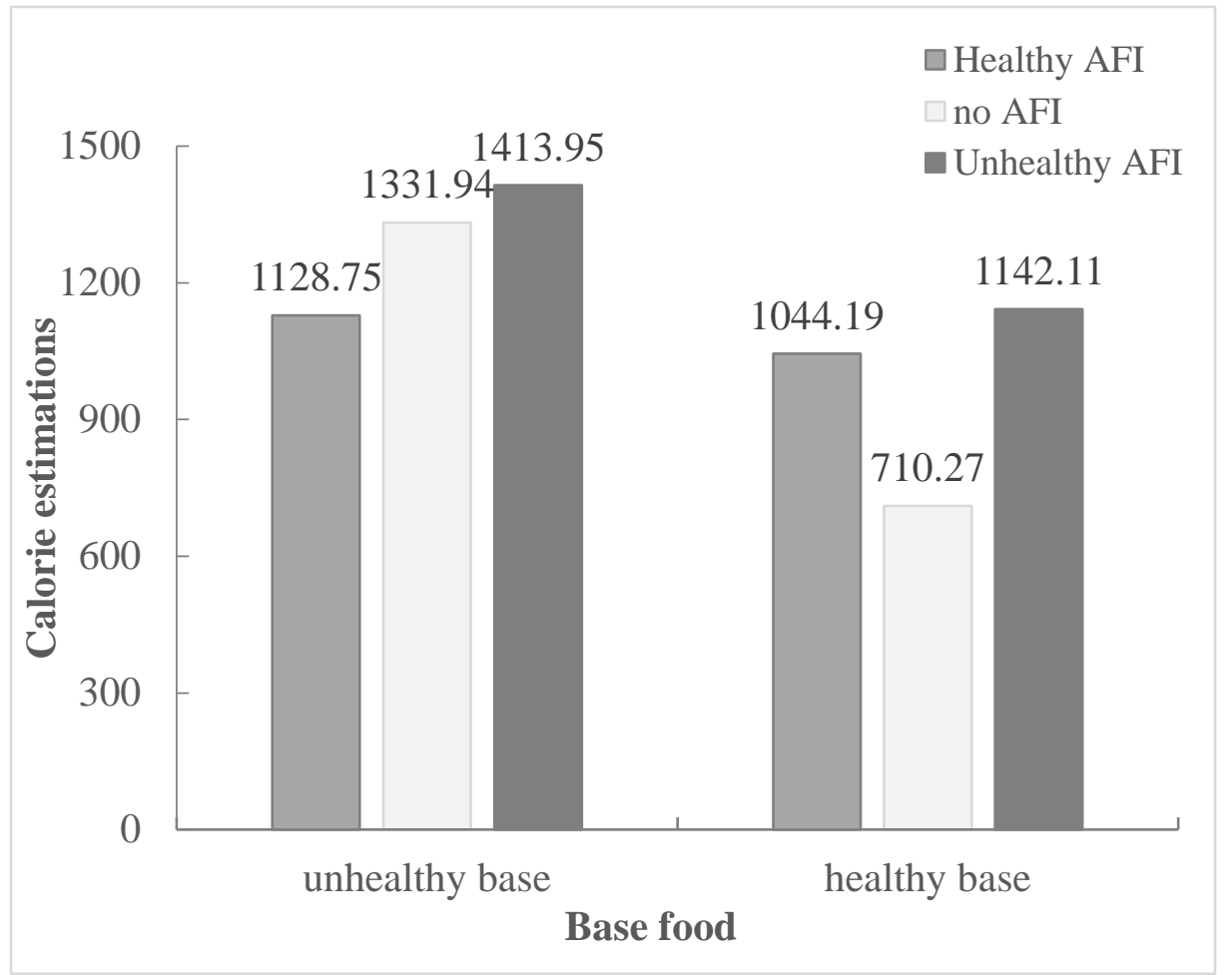

Figure 1 Results of calorie estimations of Study 1a

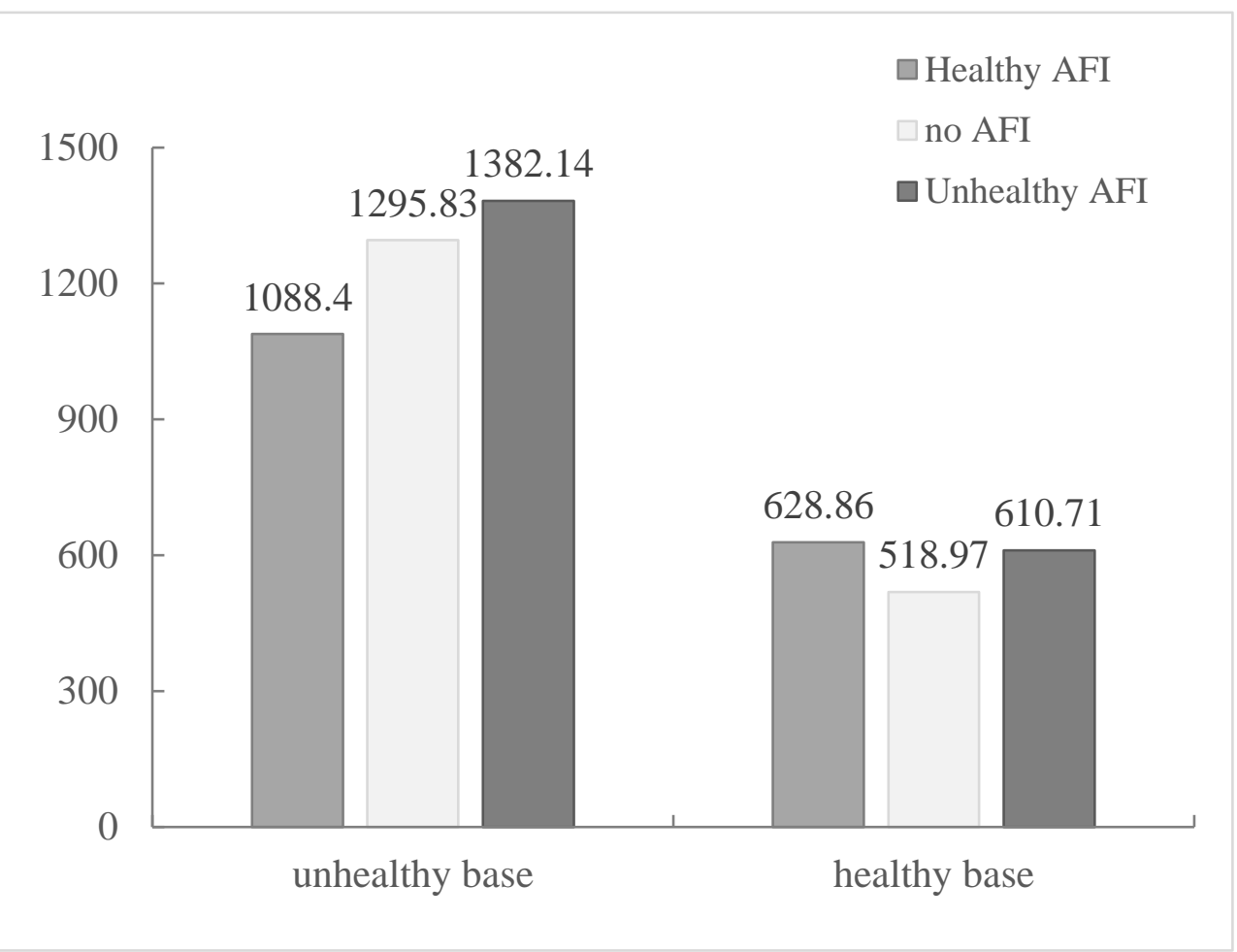

Figure 2 Results of calorie estimations of Study $1 \mathrm{~b}$ 


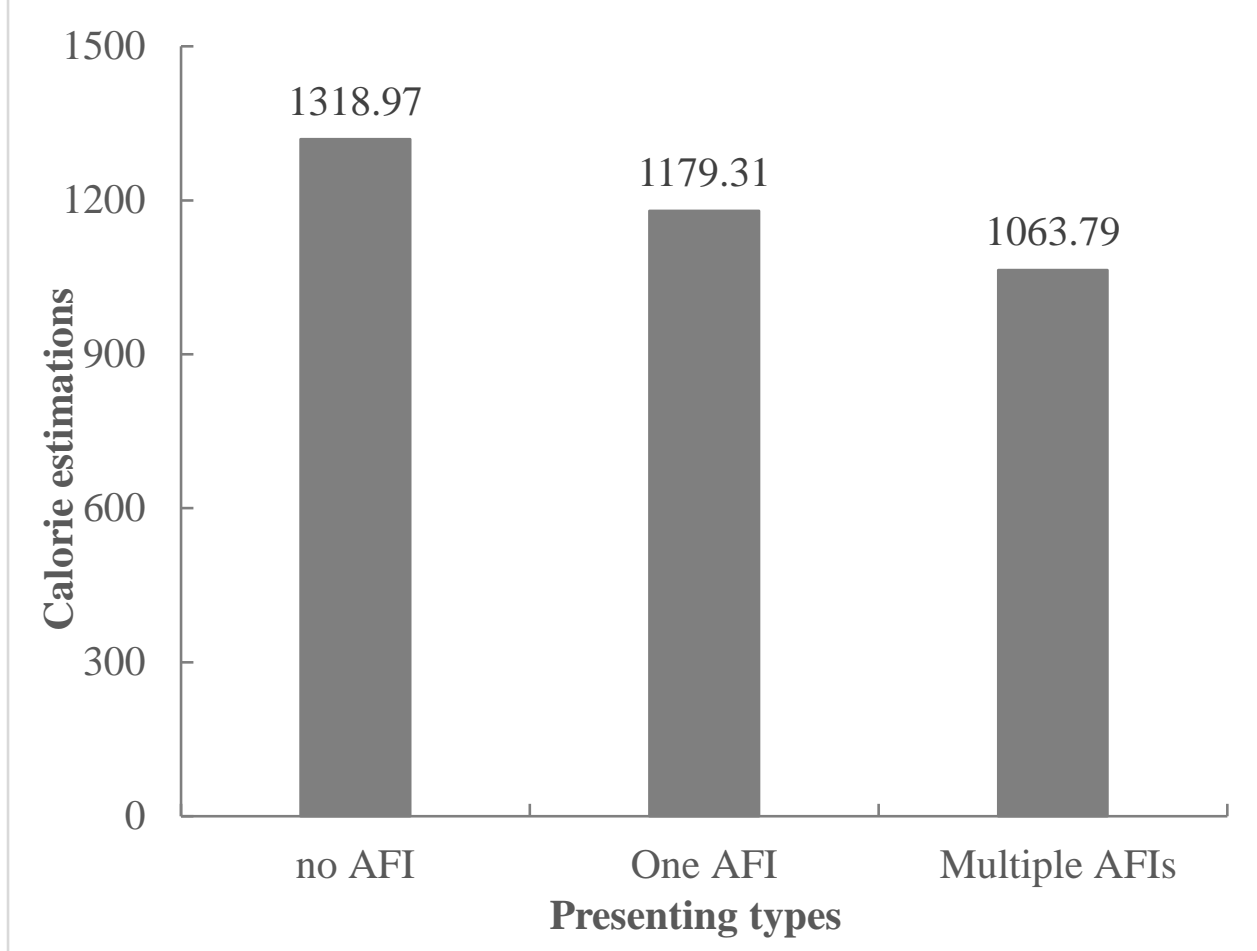

Figure 3 Results of calorie estimations of Study 3

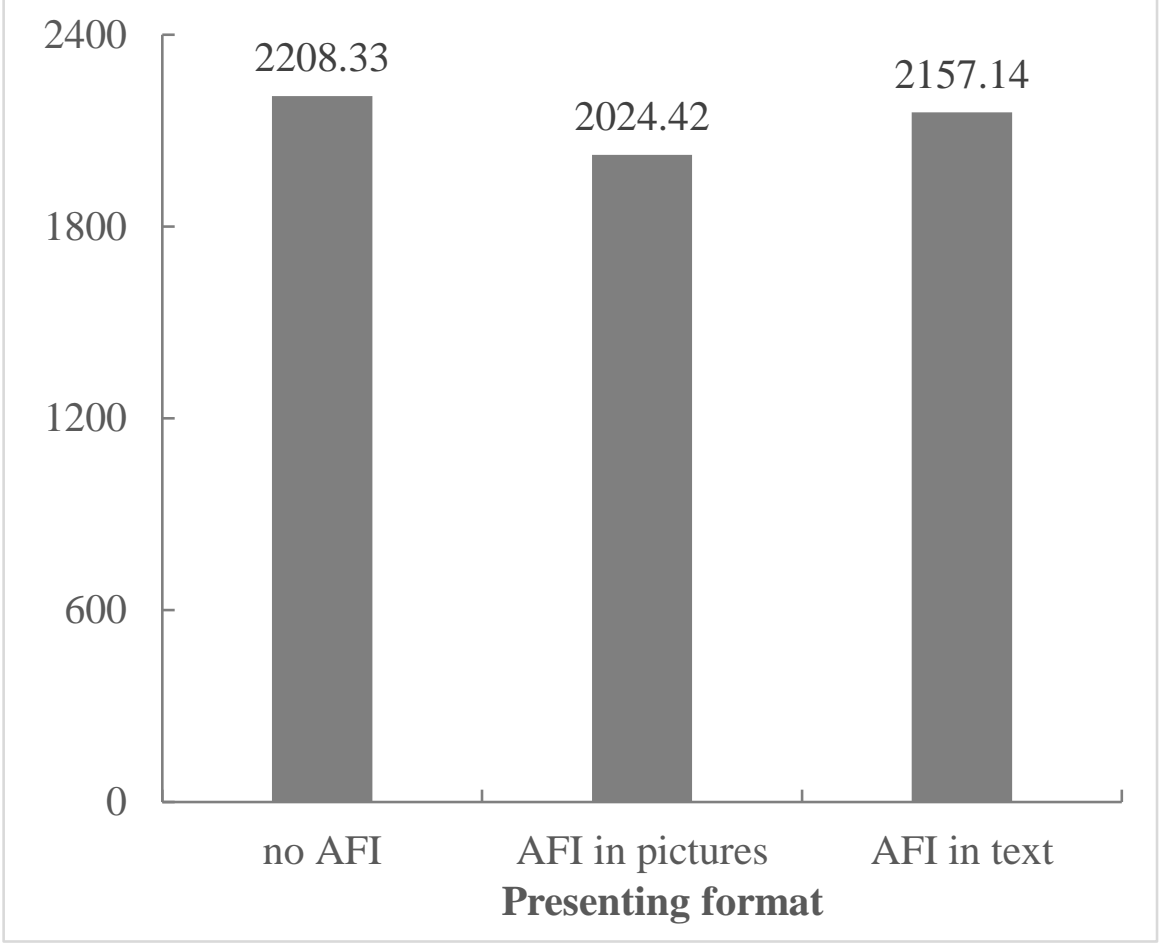

Figure 4 Results of calorie estimations of Study 4 
Appendix 1. Experimental Stimuli in Study 1A -Unhealthy Base Food

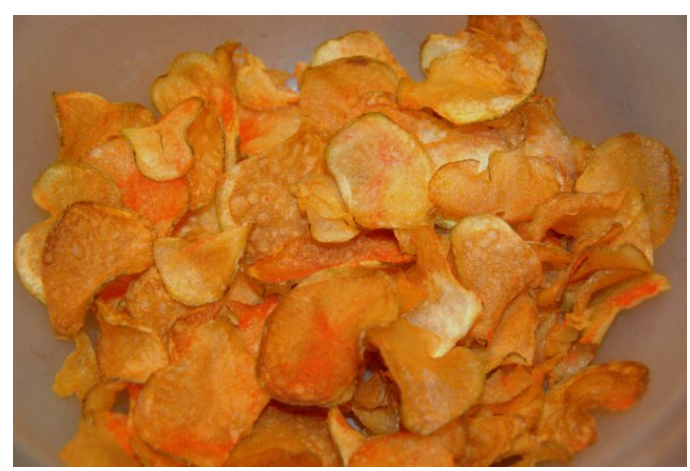

Reference: origin homemade crisps

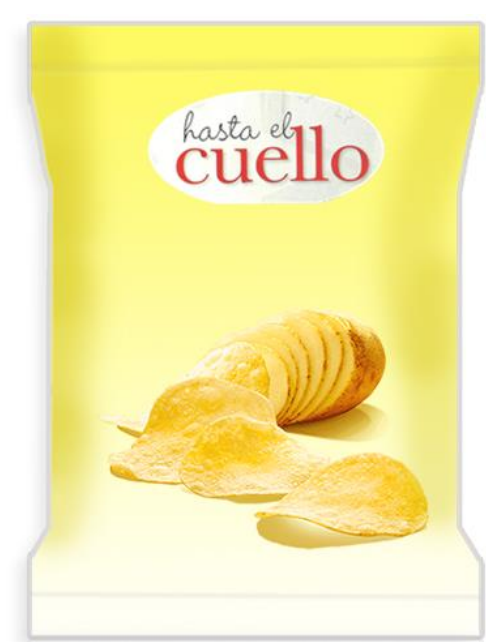

Unhealthy base food without AFI

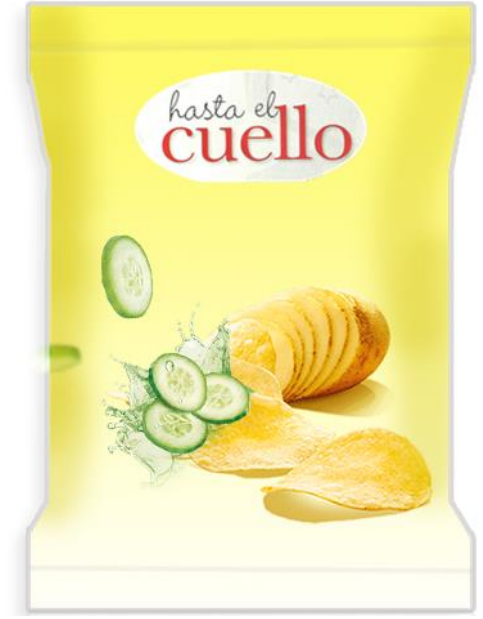

Unhealthy base food with healthy AFI

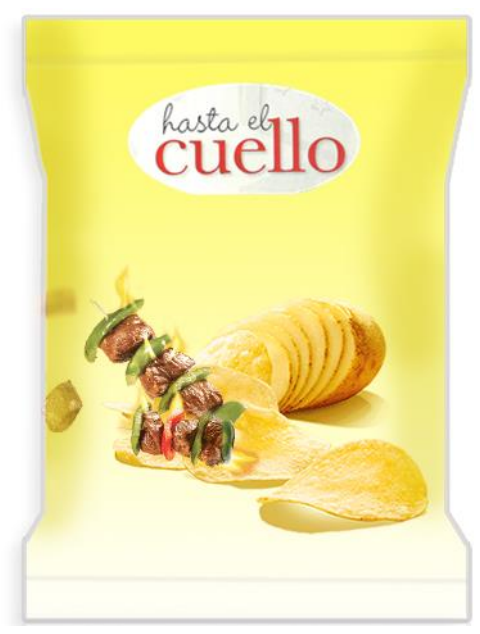

Unhealthy base food with unhealthy AFI 


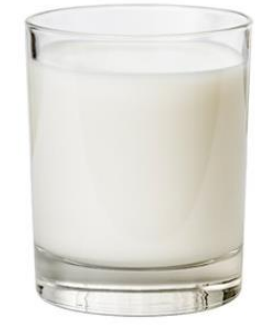

Reference: raw milk

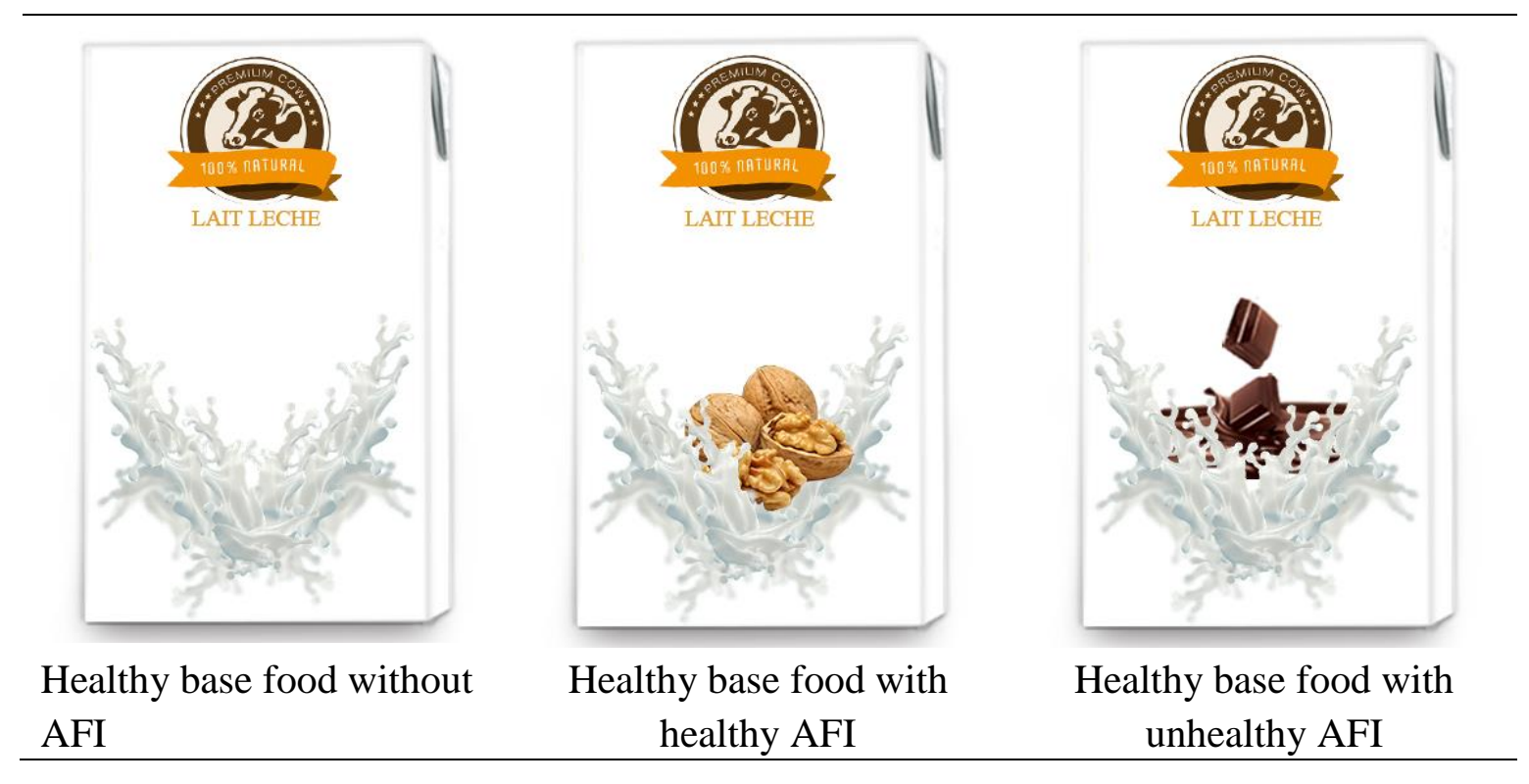




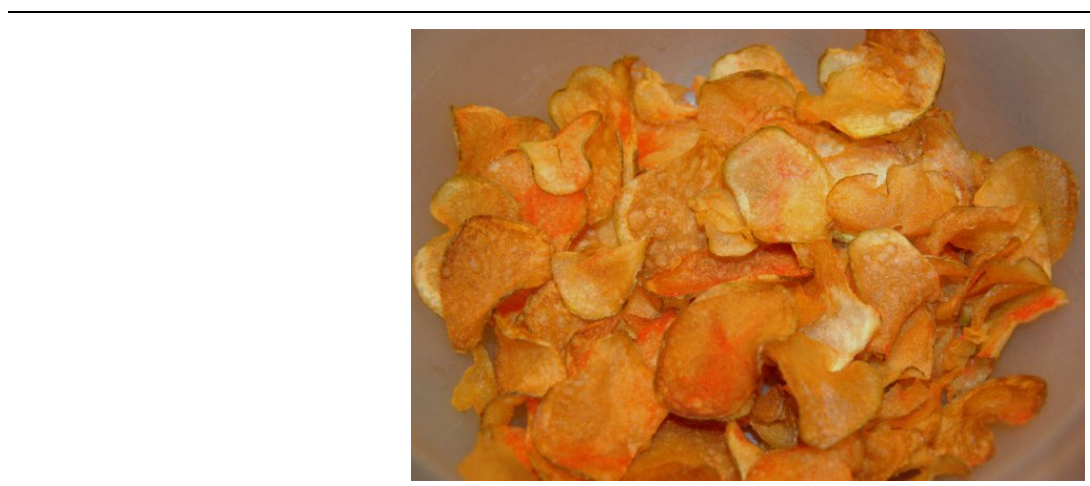

Reference: origin homemade crisps

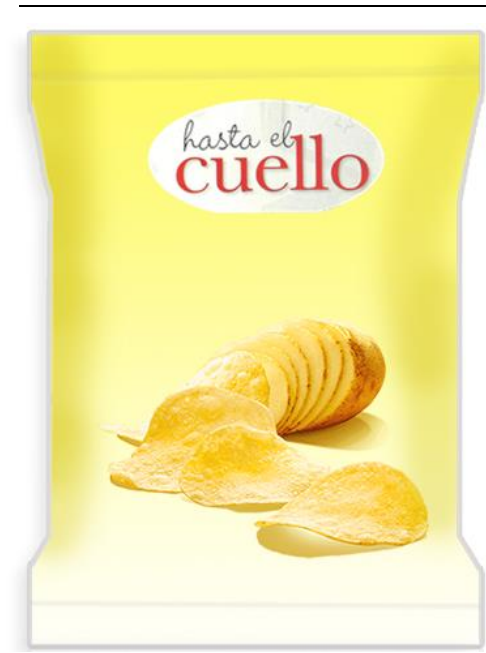

Unhealthy base food without AFI

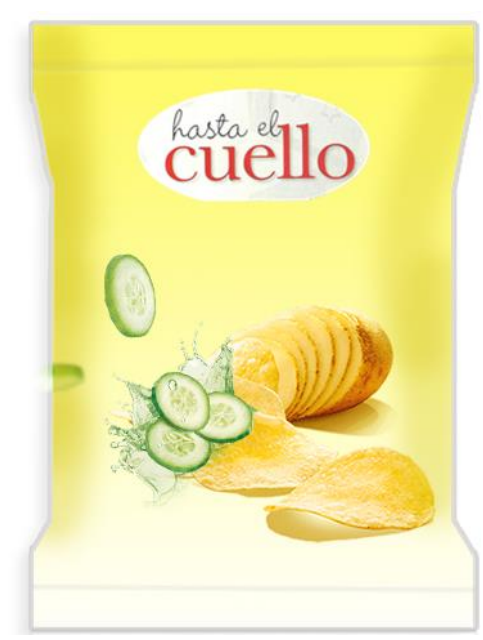

Unhealthy base food with healthy AFI

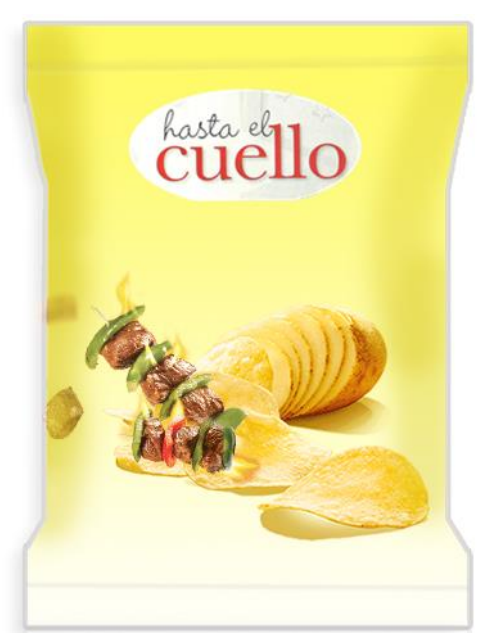

Unhealthy base food with unhealthy AFI 


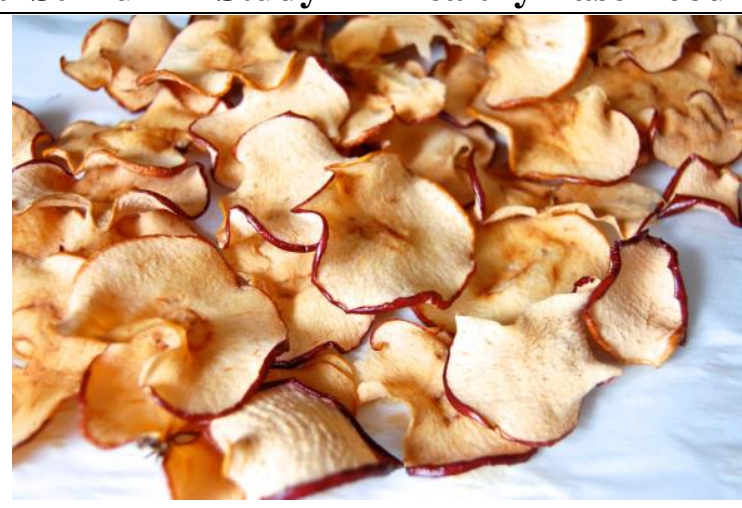

Reference: homemade apple chips

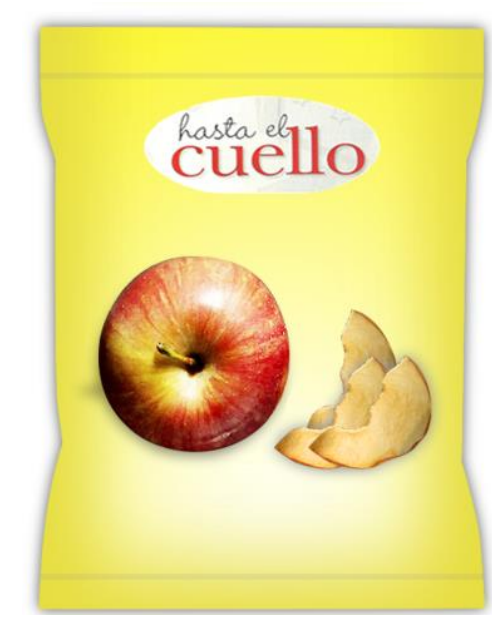

Healthy base food without AFI

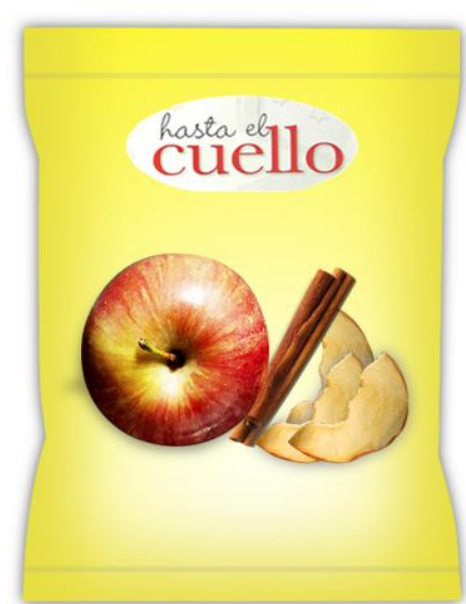

Healthy base food with healthy AFI

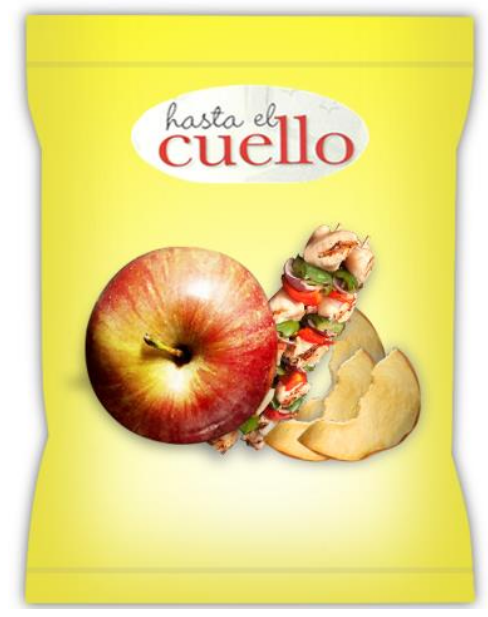

Healthy base food with unhealthy AFI 


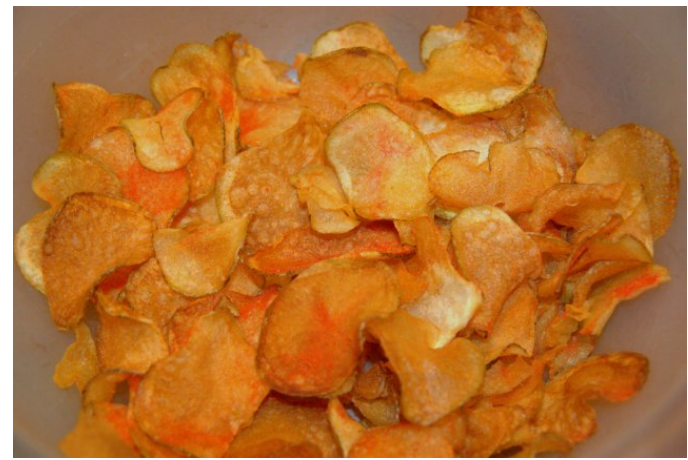

Reference: origin homemade crisps

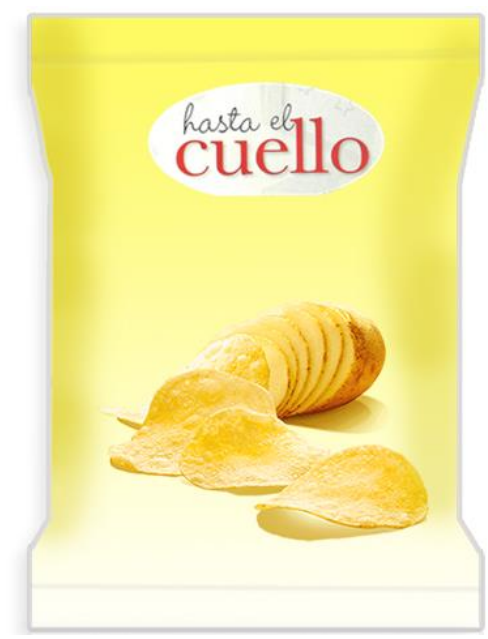

Unhealthy base food without AFI

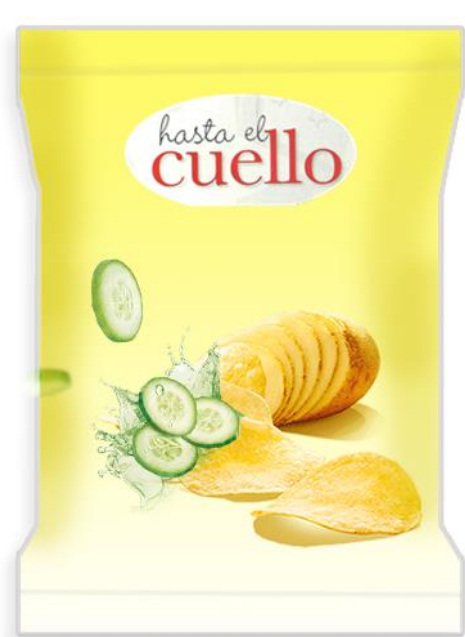

Unhealthy base food with healthy AFI 
Appendix 4. Experimental Stimuli in Study 3

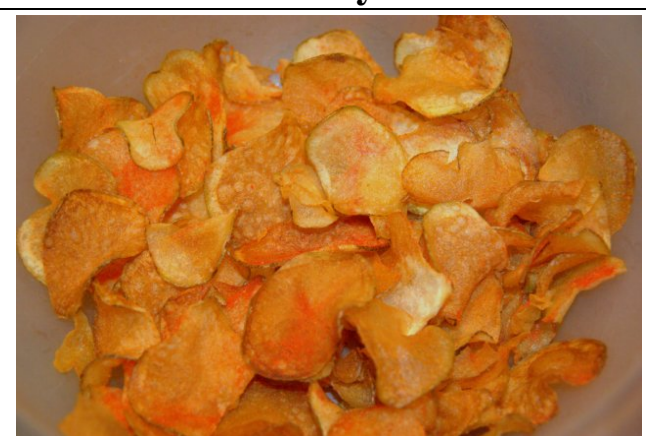

Reference: homemade crisps

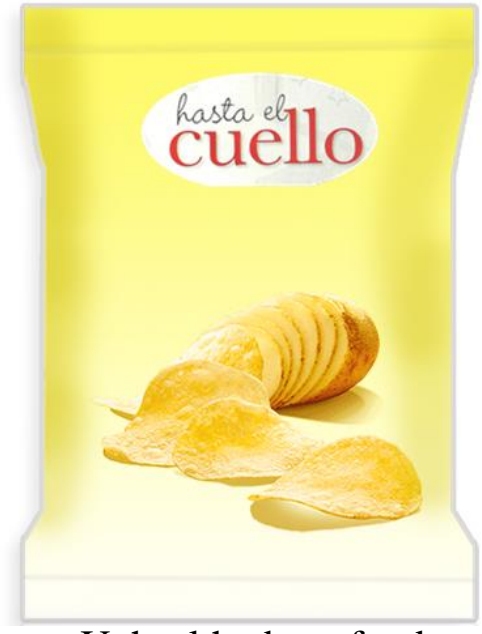

Unhealthy base food without AFI

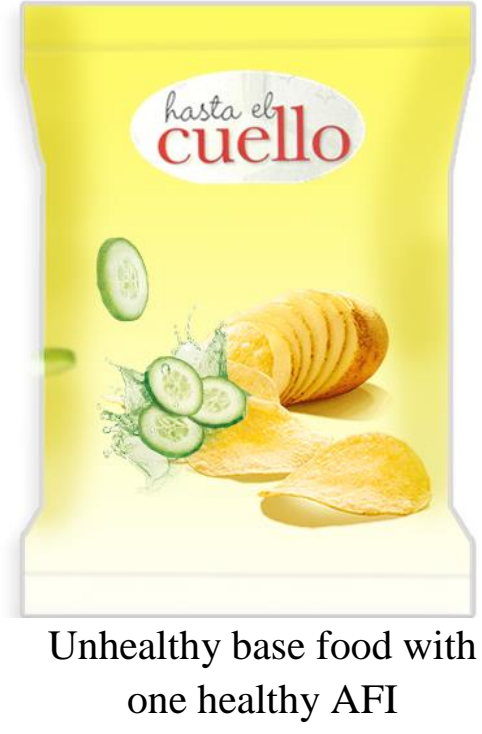

one healthy AFI

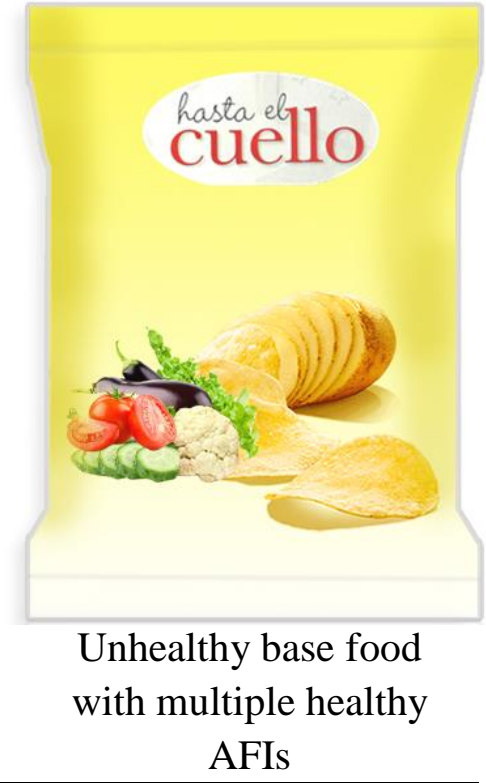




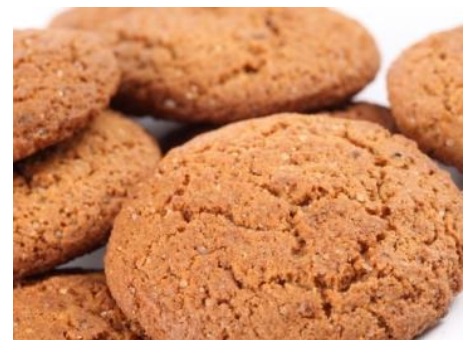

Reference: handmade cookies
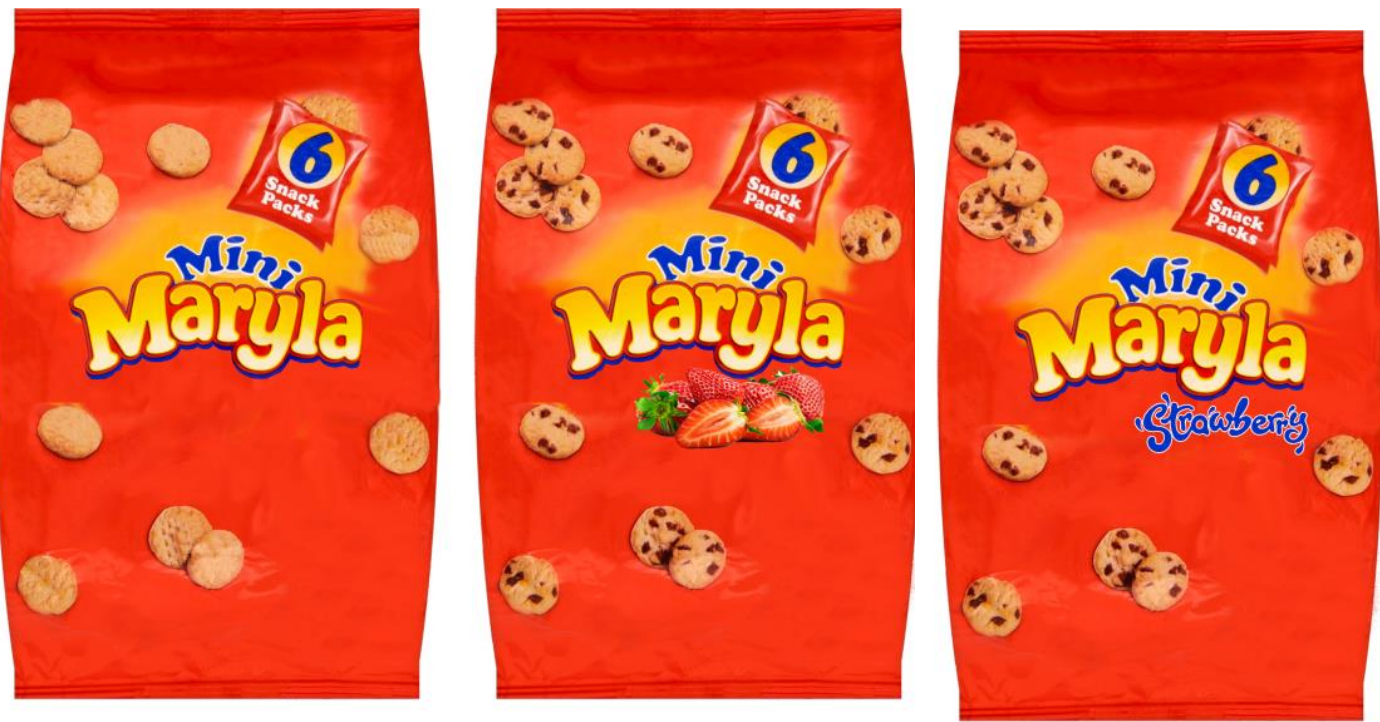

Unhealthy base food without AFI
Unhealthy base food with Unhealthy base food with healthy AFI in picture healthy AFI in words 
Appendix 6. Distribution of Responses
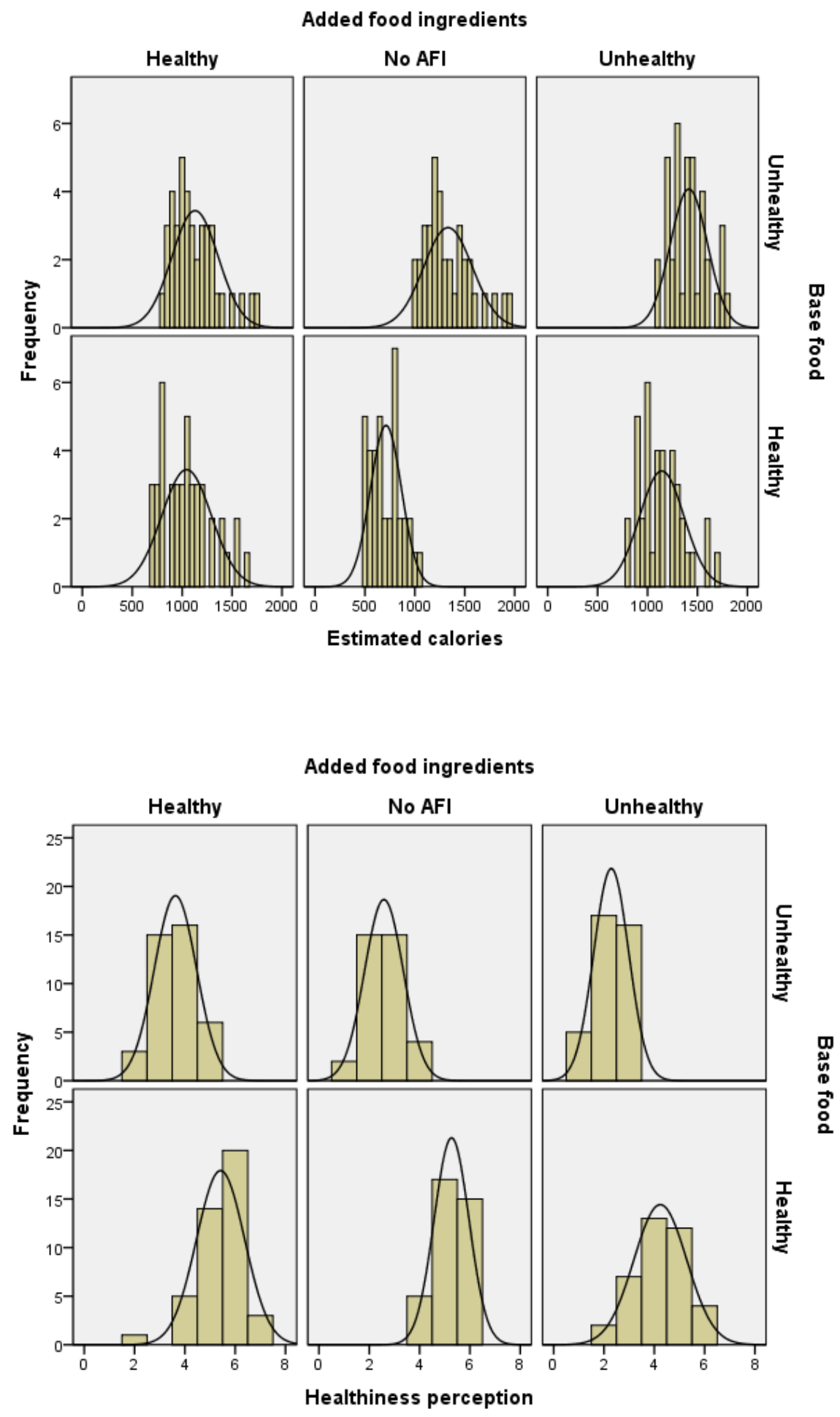

Study 1a 

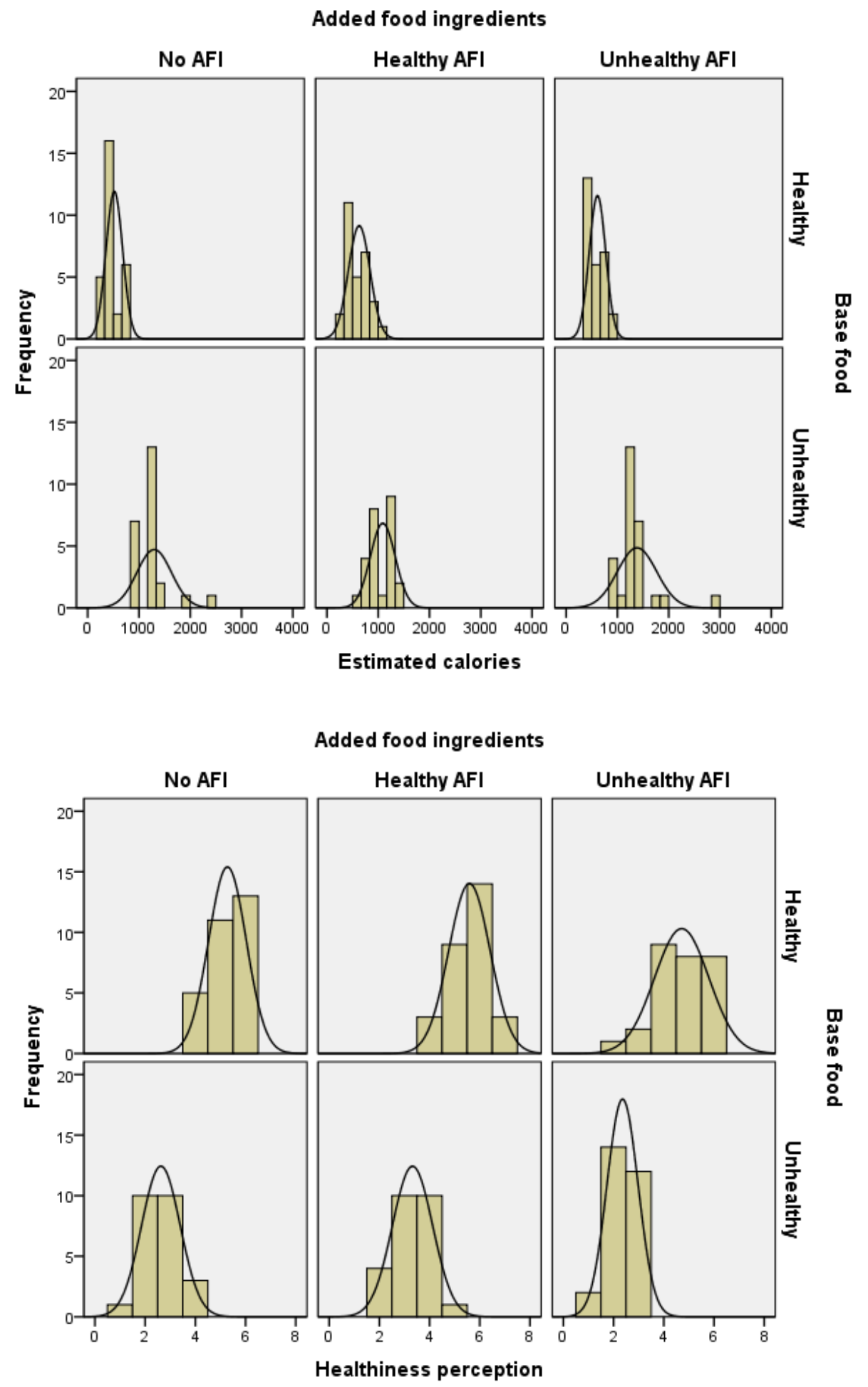

Study 1b 

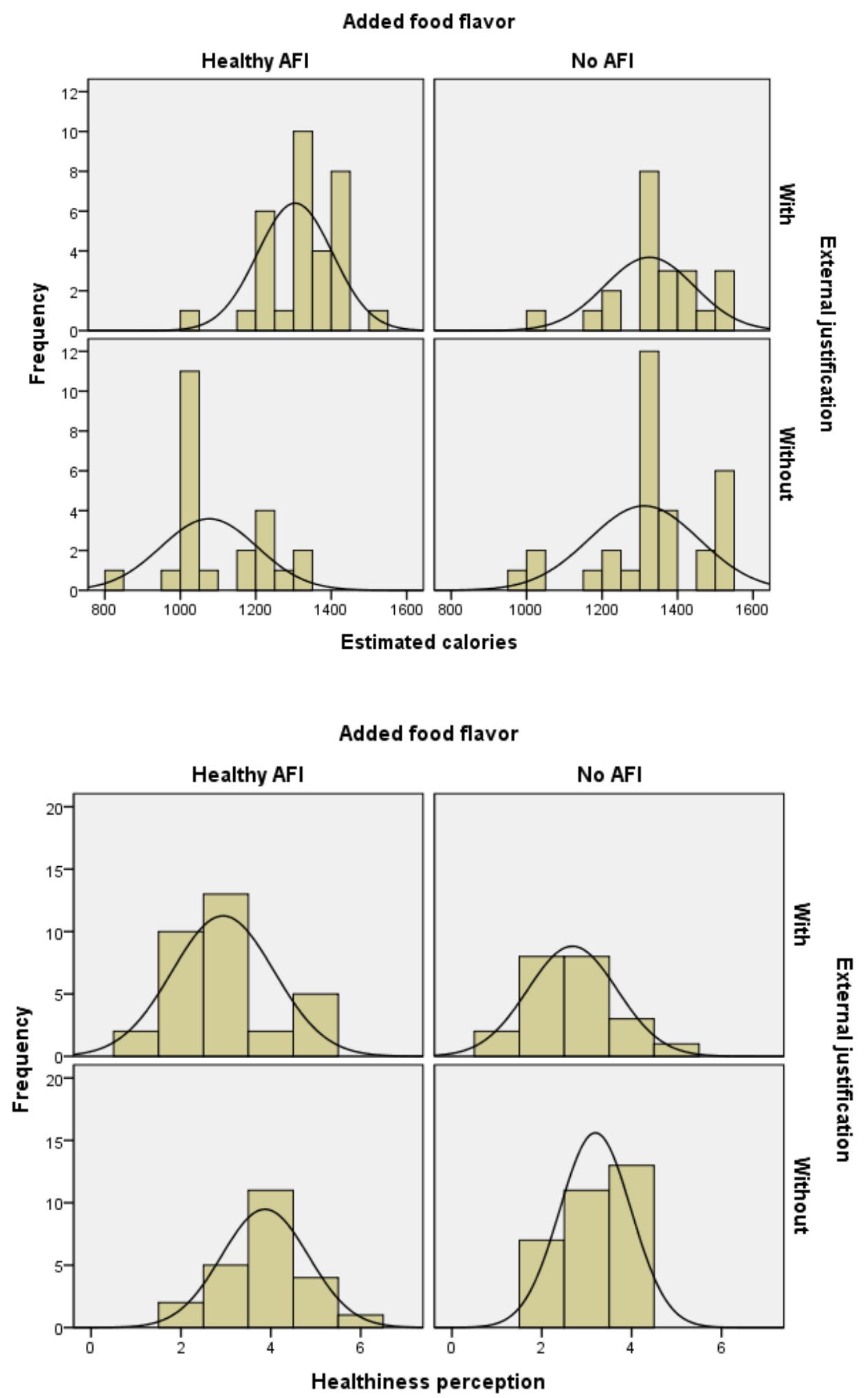

Study 2 

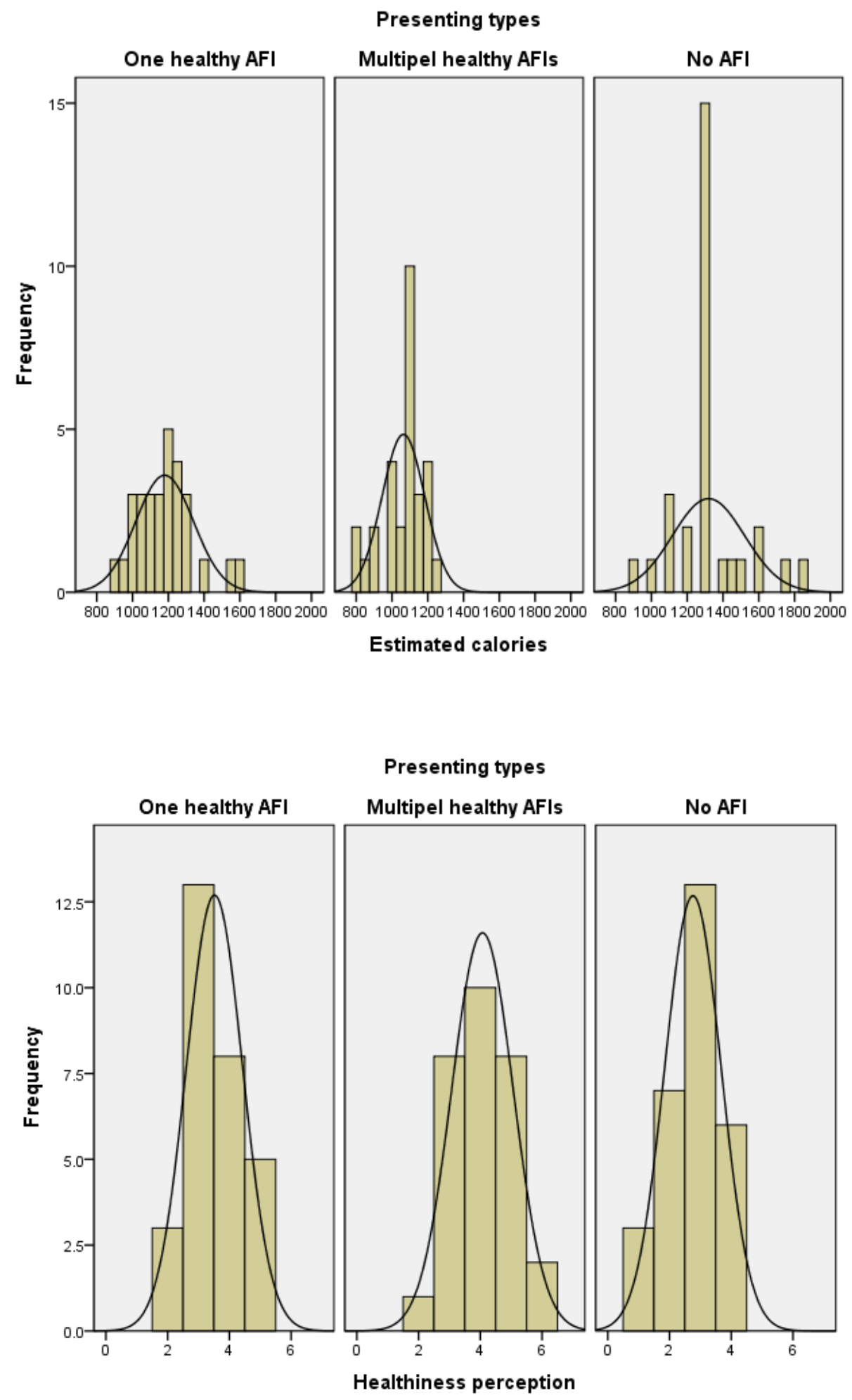

Study 3 

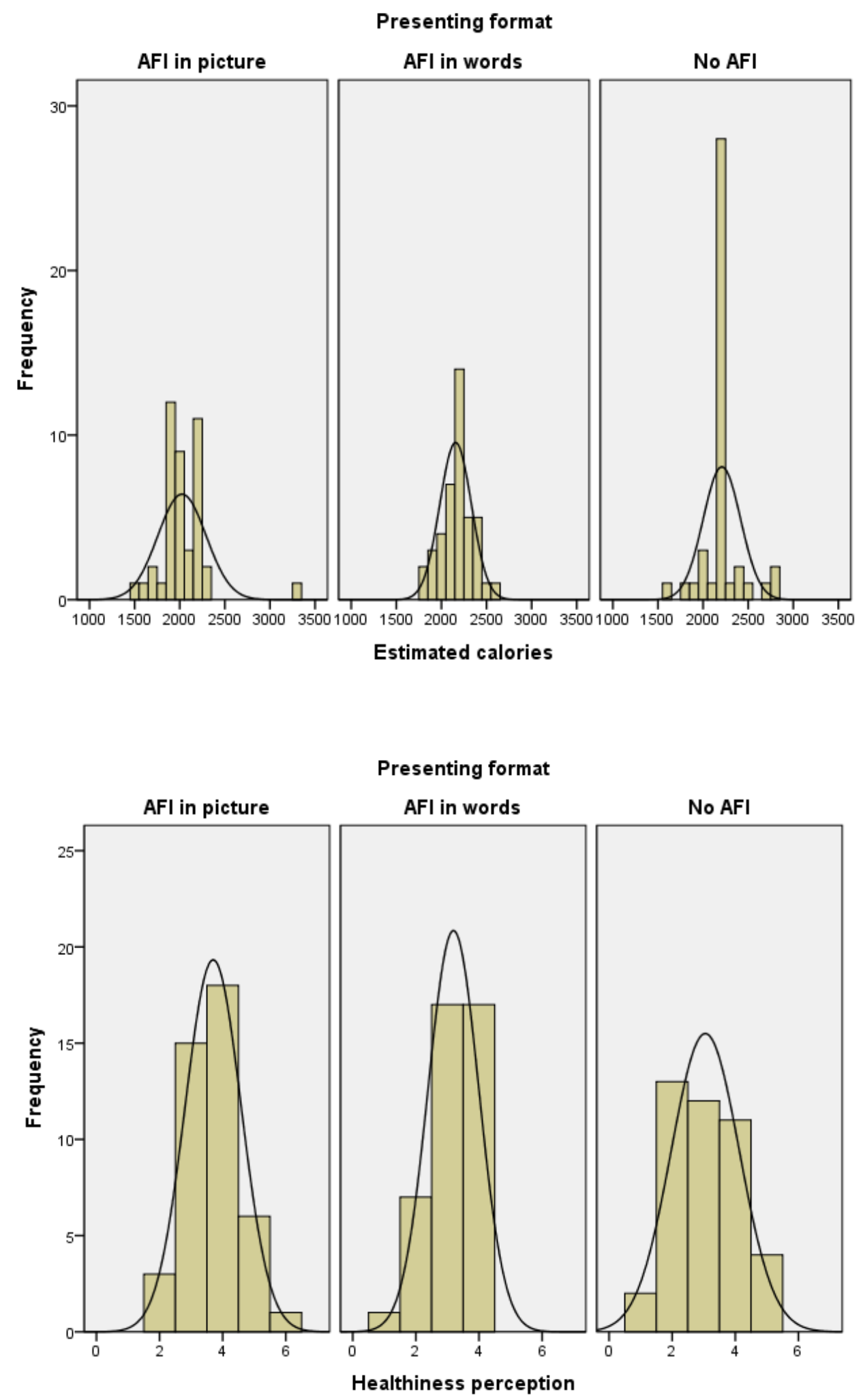

Study 4 